\title{
Hermann Cohen's Das Princip der Infinitesimal-Methode: The History of an Unsuccessful Book
}

\author{
Marco Giovanelli
}

\begin{abstract}
This paper offers an introduction to Hermann Cohen's Das Princip der Infinitesimal-Methode (1883), and recounts the history of its controversial reception by Cohen's early sympathizers, who would become the so-called 'Marburg school' of Neo-Kantianism, as well as the reactions it provoked outside this group. By dissecting the ambiguous attitudes of the best-known representatives of the school (Paul Natorp and Ernst Cassirer), as well as those of several minor figures (August Stadler, Kurd Lasswitz, Dimitry Gawronsky, etc.), this paper shows that Das Princip der Infinitesimal-Methode is a unicum in the history of philosophy: it represents a strange case of an unsuccessful book's enduring influence. The "puzzle of Cohen's Infinitesimalmethode," as we will call it, can be solved by looking beyond the scholarly results of the book, and instead focusing on the style of philosophy it exemplified. Moreover, the paper shows that Cohen never supported, but instead explicitly opposed, the doctrine of the centrality of the 'concept of function', with which Marburg Neo-Kantianism is usually associated.
\end{abstract}




\section{Introduction}

Hermann Cohen's Das Princip der Infinitesimal-Methode (Cohen, 1883) was undoubtedly an unsuccessful book. Its devastating reviews are customarily mentioned in the literature, but less known and perhaps more significant, is the lukewarm, and sometimes even hostile, reception the book received from Cohen's early sympathizers. Some members of the group dissented publicly, while others expressed their discomfort in private correspondence. Nevertheless, Das Princip der Infinitesimal-Methode has been enormously influential in the history of Neo-Kantianism. Despite its cumbersome style and shaky conclusions, the book seems to have emanated an almost totemic aura inside the little group of scholars gathered around Cohen, which, at the turn of the century, would become the 'Marburg school'. While the members could not endorse Cohen's results without reservations, caveats, or qualifications, they still had to defend the book from attacks and sarcastic comments coming from outside Marburg, as though the identity of the entire school were being threatened. To use Gregory B. Moynahan's expression, one could call the surprising impact of this fundamentally unsuccessful book "the puzzle of Cohen's Infinitesimalmethode" (Moynahan, 2003, 3).

This paper was written with the conviction that the time is now ripe to address, if not solve, this puzzle. In the last several decades, interest in Marburg Neo-Kantianism seems to have spread to English-speaking historiography of philosophy (Makkreel and Luft, 2010). Historians focusing on German post-Kantian philosophy have begun to extend their interests beyond the golden age of classical idealism (Beiser, 2014). Those working on the emergence of twentieth-century philosophy of science have dedicated increasing attention to the role played by the Marburg school (cf. e.g., Friedman, 2000, 2010 Heis, 2011; Ryckman, 2005). Scholars often seem to unilaterally focus on Ernst Cassirer and sometimes Paul Natorp - the other leading Marburg figures-but the translation of Andrea Poma's monograph (Poma, 1997) has reintroduced Cohen's work into the discussion. Recently, even Das Princip der Infinitesimal-Methode itself has attracted some interest, from the perspective of the history of ideas and culture (Moynahan, 2003), of the history of philosophy Edgar, 2014 and also the philosophy of mathematics (Mormann and Katz, 2013). However, as far I can see, the literature still needs a detailed reconstruction of the path that led Cohen to write Das Princip der Infinitesimal-Methode, and more importantly, a history of its reception among both the 'big shots' of the Marburg community, and the minor but relevant figures gravitating around Cohen at the time (even if Schulthess, 1984 is still an invaluable source). The present paper seeks to fill this gap, and to offer tools to chip away at, if not quite break through, the infamous impenetrability of Cohen's prose.

This paper will hew to the following chronology. After an early attempt to read Kant's principle of the Anticipations of Perception through the lens of nineteenth-century psychophysics, at the turn of the 1880 s Cohen $(1883)$ became convinced that he should change course and try to understand Kant's second principle by historically reconstructing the discovery of the infinitesimal calculus (section 3). Despite the negative reception of Das Princip der Infinitesimal-Methode both within the Marburg community and outside of it (section 4), in the late 1880s Kurd Lasswitz (1890) adopted Cohen's approach in his own historical research, with some success (section 5). Although Cohen (1896) was less than enthusiastic, at the turn of the century Lasswitz's insight was echoed in the young Cassirer's Leibniz monograph (Cassirer, 1902). In this book, despite using Cohen's language, Cassirer could not hide his dissent (section 6). After the publication of the first volume of Cohen's system of philosophy (Cohen, 1902), by the 1910s the Marburg community seems to have split into two factions - an orthodox Cohenian front represented by Dimitry Gawronsky (1910), and a critical front containing the most representative members of the school, Natorp (1910) and Cassirer (1910) (section 7). Cohen himself did not fail to notice the latter fact. By the time of Cohen's retirement in 1912, the school, while celebrating his work, 
was rife with internal tensions and conflict, a portentous sign of its decline (section 8).

In retrospect, Das Princip der Infinitesimal-Methode seems to have been an unsuccessful book with a small and controversial legacy. Outside Neo-Kantian circles it never rose to the status of a respected monograph on the history and philosophy of the differential calculus, in contrast to other products of the Neo-Kantian historiography of science (Cassirer, 1906a, 1907a Lasswitz, 1890). In addition, within the Marburg community, Cohen's philosophy of the infinitesimal calculus seems to have been a source of embarrassment. Even the most sympathetic readers were puzzled by Cohen's mystical use of the 'differential' $d x$ as the origin of the finite quantitative difference $x$. As in mainstream presentations of the calculus, they insisted, Cohen should have emphasized the role of the differential quotient $d y / d x$, in which the relation between the finite differences $y / x$ is preserved even when they vanish. After all, as Natorp and Cassirer pointed out, among others, this is the clearest historical example of the fact that in the exact sciences the relations are independent from the relata. For those who are used to considering this the core tenet of Marburg Neo-Kantianism, it might come as a surprise that this was not the message Cohen wanted to convey - as some of his other students, like Gawronsky, did not fail to realize. Thus, paradoxically, Das Princip der Infinitesimal-Methode played no role or possibly just the role of a hindrance - in the emergence of the opposition between the 'concept of function' and the 'concept of substance', which Cassirer made a trademark of the Marburg School as a whole.

Nevertheless, Das Princip der Infinitesimal-Methode was an undeniably influential book, and its towering presence has loomed over the entire history of Marburg Neo-Kantianism. 'The puzzle of Cohen's Infinitesimalmethode' (Moynahan, 2003), as we will try to show, can easily be explained if one looks beyond the book itself, and instead focuses on the philosophical style it exemplified. "The special study of the infinitesimal principle," as Natorp recognized in a famous 1912 article celebrating the Marburg school, "reveals in a single glimpse the philosophical depth of [Cohen's] concern with the history of the exact sciences" (Natorp, 1912, 195). It is this detailed attention to the history of science that can be found again and again in Natorp's studies on Descartes, Galileo, etc., in Cassirer's great historical monographs, and in the works of many other minor figures. "Every contribution our school has made since then to the history and critique of the sciences," Natorp concluded rhetorically, though not without sincerity, "was the fruit of Cohen's inspiration" (Natorp, 1912, 195).

\section{The 'Psycho-Physical' Origins of Cohen's Interest in the Infinitesimal Calculus}

In the first edition of Kants Theorie der Erfahrung (Cohen, 1871), his first Kant monograph, Cohen dedicates several lines to the 'principle of Anticipations of Perception', the second of the synthetic principles enumerated by Kant in his Critik der reinen Vernunft (A, 176). In the second edition of the book, Kant somewhat cryptically attributes an intensive magnitude to the realitas phaenomenon - the 'real' that is the object of sensation - rather than to the sensation itself, as he did in the first edition $(\bar{B}, 210)$. Noticing the difference between these two formulations of the principle, Cohen commented: "What is the real as an object of simple sensation, as an intensive quantity, in antithesis to an extensive?" : "it is the unity of the stimulus in which we objectify sensation" (Cohen, 1871, 215-216) ${ }^{1}$ Cohen is convinced that Kant's insistence in the second edition of his opus magnus on the 'real' that is the object of sensation, rather than on sensation itself, is justified by the need to find an objective correlate of sensation that exerts an influence on the senses: "the intention [...] of clarifying the real as a simple unity of the objectified stimulus

\footnotetext{
${ }^{1}$ Henceforth the letter spacing in the original has been rendered as italics..
} 
seems to me to be the reason for modifying this affirmation in the second edition" (Cohen, 1871 215).

Cohen's language here might not mean much to today's reader. In contrast, his readers at the time probably would have understood his reference to the so-called 'psychophysics', the emerging nineteenth-century science that attempted to measure the intensive magnitude of sensation in terms of its functional relation to the stimulus (Fechner, 1860 see the classical Heidelberger, 2004 for more details). The issue was hotly debated by philosophers, and one might say that the first discussions of measurability in science were motivated by the rise of empirical psychology, rather than by physics (Darrigol, 2003). In February 1878, the young philosopher August Stadler (perhaps most famous for having been Einstein's philosophy professor at the ETH Zürich at the end of the century; Beller, 2000), had finished a brief paper entitled "Über die Ableitung des Psychophysischen Gesetzes", which was published in Philosophische Monatshefte in the same year (Stadler, 1878). Stadler was a student of Friedrich Albert Lange, the author of an enormously influential history of materialism (Lange, 1866); Stadler had met Cohen in Berlin in the early seventies, as the latter was an unknown Privatdozent (Cohen, 1910, cf.).

In 1874, struck by Cohen's approach to Kant, Stadler published a monograph on Kant's teleology (Stadler, 1874), in which-setting the agenda for the Marburg interpretation of the Critik der Urtheilskraft in the coming years - he insisted on the connection between the regulative use of ideas and the principle of the formal finality of nature for the construction of a system of "empirical laws". In 1875, Stadler had already finished a second monograph, in which he pinpointed the preeminence of the "synthetic principles" over the categories (Stadler, 1876) in the Critik der reinen Vernunft. Cohen immediately elaborated on Stadler's results in his 1876/77 book on Kant's ethics (Cohen, 1877). Here, for first time, Cohen identified the 'transcendental method' as the core of Kantian philosophy: the synthetic principles are a condition for the possibility of the 'fact of science' (Cohen, 1877, 20ff.) - an expression that would become the key of Marburg Neo-Kantianism; and at the same time, these principles are the 'general laws of nature' of which the empirical laws are only specifications (Cohen, 1877, 90ff.).

Stadler's 1878 paper on psychophysics was apparently free of philosophical implications. Stadler investigated the so-called Weber-Fechner law that regulates the relation between the stimulus $(\beta)$ and the sensation $(\gamma)$ (Heidelberger, 2004). He argued, against Fechner, that according to Weber's findings, if one imagines the stimulus gradually increasing (let's say, from a weight of $10 \mathrm{~kg}$ to twice that) not all of the infinite possible values between 10 and $20 \mathrm{~kg}$ can be perceived, only those for which the equation $\Delta \beta=c \beta$ holds (where $c$ is a constant that is different for different senses). That is, the difference between two weights can only be perceived when the stimulus difference is above the so-called threshold (we can perceive the difference between 10 and $15 \mathrm{~kg}$, but probably not between 10 and $10.01 \mathrm{~kg}$ ): "not every $\Delta \beta$ corresponds to a variation of the sensation, rather $\Delta \gamma$ remains zero for all values $\Delta \beta>c \cdot \beta$ " (Stadler, 1878, 219).

Consequently, according to Stadler, one cannot substitute Weber's finite differences with infinitesimally small $d \beta$ and $d \gamma$ and "represent the reciprocal correlation of the stimulus and of the sensation through a continuous function or a curve" (Stadler, 1878, 220). Fechner had presented the relation between stimulus and sensation in the form $d \gamma=\frac{K \dot{\alpha} \hat{\beta}}{\beta}$, (where $K$ is constant depending on experiments; Fechner, 1860, 2:10); sensation can be measured as the integral $\int d \gamma$, as a summation of infinitesimally small increments. Integrating the relationship, Fechner recovered the logarithmic formula which still bears his name (Fechner, 1860, 2:12ff.): the strength of the sensation is the logarithm of the strength of the stimulus (Fechner, 1860, 2:19). However, according to Stadler, there is nothing in Weber's laws to justify this conclusion: "the essence of the relation between $d \beta$ and $d \gamma$," Stadler concludes, "is discontinuity. The logarithmic curves, with which one attempts to represent the psycho-physical law, lack empirical truth" (Stadler, 1878, 223).

Stadler's interest in this topic might appear puzzling. However, the reformulation of the 
Anticipations of Perception that he suggested in his 1876 monograph (Stadler, 1876) - in particular, his insistence that the continuity of sensation cannot be deduced a priori - might give a glimpse of what he was driving at(Stadler, 1876, 71-72). The philosophical intent of Stadler's critique of Fechner becomes more explicit in a paper that Stadler published in 1880 on the Philosophische Monatshefte, "Das Gesetz der Stetigkeit bei Kant" (Stadler,1880). Stadler shows Kant's ambiguous attitude towards the question of the continuity of the intensive magnitude. In the Anticipations of Perception, Kant claims that the intensive magnitude of sensation is continuous only in the weak sense, that between every degree and nothing one can always think of another arbitrary smaller degree. Nothing can be said about the continuous variation of degree (B, 212-213). However, in the 'Beweis' of the second analogy of experience, Kant seems to defend the stronger claim, that the intensive magnitude of sensation arises from 0 to a certain degree in a continuous manner, running through all intermediate degrees $(\mathrm{B}, 255-256)$.

Stadler's paper seems to be without theoretical ambition, and it is based on a detailed textual analysis. However, although it is "only in passing," he does note "that modern psychology has not offered any reason to reshape Kant's concept of the degree of sensation" (Stadler, 1880, 585). Modern psychophysics does not permit any a posteriori demonstration of what Kant attempted in vain to demonstrate a priori. Psychophysics postulates that the process of the emergence of a sensation runs through all intermediate degrees, even if this passage is so rapid that it remains unnoticed. However - and this was the result of Stadler's 1878 paper - this postulate is far from being self-evident: "as far as intensity is concerned, in my opinion, psycho-physical research has instead shown the discontinuity in psychical transition in relation to the continuous growth of the stimulus" (Stadler, 1880,585-586). Experience seems to show that the stimulus, e.g., a weight, can be increased to a certain degree without causing any change in the corresponding sensation.

On 24 February 1881, Cohen wrote to Stadler that he fully agreed with the results of his paper. And he also added: "I have outlined a formulation of the Anticipation in which your previous concerns seem to be acknowledged and at the same time eliminated" (Cohen to Stadler, 24. Feb. 1881; Cohen, 2015, 128-129). It seems plausible that at this point Cohen had begun reading Kant's Anticipations of Perception quite differently, possibly outside the framework of psychophysics. The relation between differential and intensive magnitudes, which, according to Stadler, psychophysics had failed to establish, could be thought of in a fundamentally different way.

The very attempt to interpret Kant's second principle psychophysically might surprise today's reader. However, this approach was part of a vast 'research program' put forward by the rising Marburg school, which in turn was inserted into a wider philosophical discussion about the measurability of psychological phenomena that was motivated by the rise of empirical psychology (Darrigol, 2003). At the end of the 1870s, Cohen had become a professor in Marburg, succeeding Lange (who died prematurely in 1875, Cohen, 1876 cf. Ebbinghaus, 1959). The first Jewish professor at a German University, Cohen began to attract a group of students who were primarily drawn to his ability as a lecturer. According to the guideline of the Prussian Kultusministerium, the philosophy faculty in Marburg used to offer scientific Preisaufgaben (essay prizes) with the intent of supporting students (Sieg, 1994, 130f.).

For the 1880 prize, suggested by Cohen, ${ }^{2}$ the candidate had to "[e]xplain Kant's mathematical principles" ; in particular, "the second principle [Anticipations of Perception ], should be evaluated with respect to the problem of psychophysics" (cit. in Sieg, 1994, 131, n. 31). The recipient of the prize was Adolf Elsas, an assistant at the department of physics and mathematics. In 1886, Elsas published the pamphlet Über die Psychophysik. Physikalische und erkenntnisstheoretische

\footnotetext{
${ }^{2}$ For an overview of the Preisaufagaben suggested by Cohen till 1893, see Holzhey, 1986, 1:381f..
} 
Betrachtungen (Elsas, 1886; cf. Heidelberger, 2004, 229ff.). In 1881, Ferdinand August Müller, who was Cohen's doctoral student, published the booklet Das Axiom der Psychophysik und die psychologische Bedeutung der Weber'schen Versuche (Müller, 1882), where again he sharply criticized psychophysics' attempt "to measure the psychological [das Psychische]" (Müller, 1882 48; cf. Heidelberger, 2004, 215ff.).

Müller also explicitly refers to Cohen's interpretation of the relation between reality and sensation: "by defining the real that corresponds to sensation in the object as 'stimulus', Cohen developed in a highly significant way Kant's doctrine of the intensive magnitudes" (Müller, 1882 ,55). In particular, Müller attempted to show that the intensive magnitudes should not be attributed to sensation but to the stimulus, which must be defined $\grave{a}$ la Kant as what produces some degree of influence on the senses (B, 208). According to Müller, "physics measures intensive magnitudes and it is therefore the task of physics to measure the magnitude of the stimulus" (Müller, 1882, 55). Müller refers, for instance, to Bunsen's method of measuring the intensity of a light source. In this sense it is not the sensation that has magnitude, but only the stimulus: "sensation is not a function of the stimulus, but the stimulus is the object of sensation" (Müller, $1882,56)$; Müller believed this showed that "[t]hat the sensation cannot be expressed in numbers at all," i.e., it cannot be measured (Müller, 1882, 58).

Elsas criticized Müller's formulation in his otherwise positive review of Müller's book (Elsas, 1884). According to Elsas, only sensation has an intensive magnitude (which is not measurable), whereas physics measures only extensive magnitudes (for instance, temperature through a pointer reading on a measuring instrument) (Elsas, 1884, 134). Stadler mounted a similar criticism of Müller in his monograph Kants Theorie der Materie (Stadler, 1883), probably the first such work on Kant's Metaphysische Anfangsgründe der Naturwissenschaft. Stadler agreed with Müller that "only the stimulus can be measured, not sensation"; however, this did not mean that "intensive magnitude can only be attributed to the stimulus," as Müller claims (Stadler, 1883, 248, n. 24). On the other hand, according to Stadler, only sensation has intensive magnitude, but this is an internal psychological determination, which "in its own nature is not measurable" (Stadler, 1883 $61)$.

This discussion is interesting insofar as it shows how the early 'Marburg' debate on Kant's category of reality, intensive magnitude and sensation developed within the framework advanced by Cohen. As Stadler writes, "Cohen, very happily, defined the objective correlate of the intensive magnitude of the stimulus" (Stadler, 1883, 60). The magnitude that corresponds to the stimulus of the intensive magnitude would thus be called the magnitude of the stimulus, die 'Reizgrösse' (Stadler, 1883, 60).

In Stadler's view, in empirical psychology the stimulus of sensation should ultimately be thought of as motion, as Kant himself had put it: "because only thereby [through motion] can these senses be affected" (Ak. ${ }^{3} 4: 477$ ). Kant used the expression 'moment' to indicate the "reality as cause" and, in particular, as the "cause of sensation," as something that exerts an influence on the senses, that is, as the stimulus $(\bar{B}, 211)$. The "moment is the magnitude of the force that corresponds to the intensive magnitude of the sensation" (Stadler, 1883, 60). The intensive magnitude is given in consciousness, it is a "subjective evaluation" of the stimulus, and cannot be measured (Stadler, 1883, 61).

Stadler notes that there are passages where Kant seems to attribute intensive magnitude not to sensation, but to physical determinations like 'velocity' (cf. Ak. 4:540-41). However, one should resist confusing this intensive magnitude with the intensive magnitude of sensation. According to Stadler, Kant "did not want to identify it [the intensive magnitude of velocity] at all with

\footnotetext{
${ }^{3}$ Henceforth, Ak. $=\mathrm{Ak}$.
} 
the intensive magnitude, which corresponds to reality" (in the sense of the category of reality) (Stadler, 1883, 37). The definition of the velocity as an intensive magnitude, Stadler pointed out, was only an analogy used to emphasize that the magnitude of velocity is not composed of parts, as the magnitude of space and time is.

Stadler took some pains to interpret away the passages that could support the opposite reading. He comments on Kant's reflection with the title "Über das Moment der Geschwindigkeit im Anfangsaugenblick des Falls" (Ak. 14, Refl. 67, 1788-91) where Kant attributes an "intensive magnitude' to the 'moment of velocity' - that is, the tendency to fall downward at the beginning of a falling motion - and conceives of the finite motion as a summation of infinitely many 'moments' (Ak. 14:495, Refl. 67). Stadler warned that one should not try to read passages like these as Kant's attempt to provide a foundation for the "objective validity of the differential calculus" (Stadler, 1883, 39). Interpreters committed to such a reading "would be in contradiction, however, with the view that Kant expressed of the infinitesimal method" (Stadler, 1883, 39).

In fact, according to Stadler, Kant considers "points and instants only as limits, not as quantities, that can themselves be defined as real" (Stadler, 1883, 39). For Kant, "the infinitesimallysmall is only a relatively-small" (Stadler, 1883, 39). In general, in Kant's work, continuity means infinite possibility of division, not composition from actual, though infinitely small parts. Stadler argues polemically that, "those who make the intensive magnitude correspond with the differential confuse the form with the content" (Stadler, 1883, 39).

\section{The History of the Infinitesimal Method: From Das Princip der Infinitesimal- Methode to the Second Edition of Kants Theorie der Erfahrung}

Stadler's book was finished in October 1883. The Vorwort of Cohen's Das Princip der Infinitesimal-Methode is dated August 1883 (Cohen, 1883). Although Stadler never refers to Cohen, Cohen himself later read these passages (Cohen, 1910) as being directed towards his coming book, of which Stadler might have read the drafts ${ }^{4}$ In a letter from 27 September 1883 to Paul Natorp - who had arrived in Marburg in the early 1880s to set up his home - Cohen, after recounting having visited a friend he shared in common with Stadler, revealed that "the Infin. Principle" was finished. He planned to send it to the "evil world" in mid-October. He asked Natorp for a sympathetic reading: "justice will speak anyway" (Cohen to Natorp, 27 Sep. 1883; Holzhey, 1986, 2:148). As we will see, these words proved quite prophetic.

Even if there is no evidence that the recipient of Stadler's criticism was Cohen, it is undeniable that Cohen's book put forward the exact project that Stadler vehemently rejected. By that time, Cohen had completely abandoned the framework of psychophysics, which had enjoyed so much success among his acolytes. He became convinced that Kant's second principle could be understood precisely by looking at the connection between the concepts of 'moment', 'intensive magnitude' and 'reality', which was suggested by the Kant passages mentioned by Stadler. According to Cohen, by establishing this connection, Kant had expressed philosophically in his principle of Anticipations of Perception, the problem that Galilei, Leibniz and Newton had tried to answer historically by introducing 'infinitesimally small quantities'. Thus, Cohen's ambitious project was to use Kant's second principle to provide nothing less than an 'epistemological foundation' for what he called the 'infinitesimal method'.

\footnotetext{
${ }^{4}$ Unfortunately the correspondence between Stadler and Cohen from this period was lost (Cohen, 2015)..
} 


\section{The History of the Infinitesimal Method: From Das Princip der Infinitesimal- Methode to the Second Edition of Kants Theorie der Erfahrung}

Stadler's book was finished in October 1883. The Vorwort of Cohen's Das Princip der Infinitesimal-Methode is dated August 1883 (Cohen, 1883). Although Stadler never refers to Cohen, Cohen himself later read these passages (Cohen, 1910) as being directed towards his coming Das Princip der Infinitesimal-Methode, of which Stadler might have read the drafts. In a letter from 27 September 1883 to Paul Natorp - who had arrived in Marburg in the early 1880s to write his Habilitation - Cohen, after recounting having visited a friend he shared with Stadler, revealed that "the Infin. Principle" was finished. He planned to send it to the "evil world" in mid-October. He asked Natorp for a sympathetic reading: "justice will speak anyway" (Cohen to Natorp, 27 Sep. 1883; Holzhey, 1986, 2:148). As we will see, these words proved quite prophetic.

Even if there is no evidence that the object of Stadler's criticism was Cohen, it is undeniable that Cohen's book put forward the exact project that Stadler vehemently rejected. By that time, Cohen, after having abandoned the framework of psychophysics, became convinced that Kant's second principle could be understood precisely by looking at the connection between the concepts of 'moment', 'intensive magnitude' and 'reality', which was suggested by the Kant passages mentioned by Stadler. According to Cohen, by establishing this connection, Kant had expressed philosophically in his principle of Anticipations of Perception, the problem that Galileo, Leibniz and Newton had tried to answer historically by introducing 'infinitesimally small quantities'. Thus, Cohen's ambitious project was to use Kant's second principle to provide nothing less than a 'foundation' for what he called the 'infinitesimal method' from the point of view of the critique of knowledge. Cohen prefers the term Erkenntisskritik (critique of knowledge) - and the corresponding untranslatable but characteristic adjective erkenntisskritisch - to the more common Erkenntisstheorie (theory of knowledge) because it was closer to the spirit of Kant's philosophy and less prone to psychologistic misunderstanding (Cohen, 1883, secc. 8, 9 and 10). The object of Cohen's investigation, he insisted, was not 'knowledge' as a psychological process, but 'science' in its historical development.

\subsection{The Infinitesimal Method and the History of Its Discovery}

Cohen was of course aware that "starting from D'Alembert mathematicians usually seek the foundation of the infinitesimal calculus in the method of limits" (Cohen, 1883 1). In the article Différentiel in the Encyclopédie (1754), D'Alembert had in fact insisted that the differential and integral calculus is not a calculus of infinitely small quantities or quotients of infinitely small quantities, but only of the limits of the ratio of two finite quantities (Diderot and d'Alembert, 1751-1772, 4:985ff.). By referring to the 'method of limits', Cohen seems to have in mind the eighteenth-century literature, i.e., authors such as the Swiss mathematician Simon L'Huilier (1786), who, drawing on D'Alembert, considered the method of limits as a sort of extension of the demonstration using the ancient 'method of exhaustion' (Cohen, 1883, 96). In general, Cohen seems to include in the category of the 'method of limits' all attempts to justify the calculus without using any methods extraneous to traditional algebra: Leibniz's own 'Archimedean-style' demonstrations, Euler's identification of the differential with zero (Euler, 1748, cf. Cohen, 1883 91ff.), Lazare Carnot's 'compensation of errors' (Carnot, 1881; cf. Cohen, 1883, 97ff.), JosephLouis Lagrange's method of power-series (Lagrange, 1797 cf. Cohen, 1883 96), etc. For Cohen, these approaches represent a sort of 'repression' of a concept that was apparently unbearable to the mathematical consciousness, the concept of the 'infinitesimally small'.

Cohen does not want to question the 'internal' legitimacy of such justifications of the 'calculus' (Cohen, 1883, 121), even if he refers us to the work of Antoine Augustin Cournot (1841) for a recent alternative approach. However, he claims that such justifications conceal the authentic motive 
that induced the 'discoverers' of the infinitesimal 'method' to introduce a new type of magnitudes unknown to previous mathematics: "This reading obscures the discovery and its tendency; the positive, autonomous, irreplaceable element that forms the basis of this new type of magnitudes is smoothed out [nivellirt]" (Cohen, 1883, 95). A proper 'foundation' of the infinitesimal calculus from the point of view of the critique of knowledge, Cohen argues, should instead try to grasp the problem that the discoverers of the infinitesimal method had tried to solve when they were forced to introduce infinitesimally small quantities.

For this reason, Cohen states at the very beginning of his controversial booklet that "nothing seems more necessary to me, and nothing more immediately useful than following, simultaneously with the unfolding of a decisive systematic idea, its historical development" (Cohen, 1883, 3). This, as we will see, would quickly become the trademark of Cohen's early circle. During the same years, Natorp had also started to produce several influential (and philologically more accurate) sketches on what he called the 'prehistory' of criticism (Natorp, 1881, 1882a b, 1884), by insisting on the necessity of "the treatment of the history of science from a philosophical point of view" (Natorp, 1882b, 228).

In precisely this same vein, Cohen insisted that the philosophical sense of the infinitesimal method could be clarified only by sketching the history of its discovery. Cohen is of course aware that "After [...] the discovery was completed and determined," the discoverers themselves attempted "to affirm and defend it [the infinitesimal method] through the traditional method of limits" (Cohen, 1883, 88). However, Cohen believes that the justification of calculus "from the point of view of the critique of knowledge [erkenntniskritische Beleuchtung] belongs to the discovery of the idea" (Cohen, 1883, 88). Cohen therefore wrote a history of the infinitesimal method and did not limit himself to abstractly determining its 'logical' foundation. This is essential in trying to make sense of his work: it is only "through the representation of scientific relations that led to the discovery of the calculus," Cohen insists, that "the possibility of understanding its significance from the point of view of the critique of knowledge is better guaranteed" (Cohen, $1883,11)$. This emphasis on a strong relationship between the histories of the sciences would become the trademark of Marburg Neo-Kantianism, and was probably the reason why Cohen's book continued to exert an influence despite its controversial results.

Cohen's reference to the category of 'reality' was of course a major source of misunderstanding among readers unconformable with his 'Kantian' jargon. Cohen surely emphasized Kant's distinction between reality (Realität) and existence (Wirklichkeit) (Cohen, 1883, 60). Consequently, "the question of the reality of the infinitesimally small can only concern their character and value," not "their existential occurrence in the material world" (Cohen, 1883, 55). However, Cohen glosses over Kant's peculiar usage of the word 'Realität', which conflicted with its everyday and philosophical use (Holzhey, 1984). This is one reason the book remained obscure to most of his non-philosophically-trained readers. On the other hand, Cohen was convinced that by precisely following the history of the infinitesimal calculus, one could properly grasp the actual meaning of Kant's category of reality.

The premise and result of Cohen's research can thus be roughly summarized as follows: In the history of science, the infinitesimal method and the concept of the infinitely small were introduced in order to solve the problem that Kant later formulated, even if only imprecisely, in the "the category of reality" and "thus in the principle of intensive magnitudes and of anticipations" (Cohen, 1883, 14). Conversely, the meaning of the category of reality and of Kant's second principle can be understood as the expression of an unavoidable problem which emerged in the history of scientific thought: "the lack of a foundation for the concept of the differential from the point of view of the critique of knowledge [erkenntnisskritisch] is at the same time the reason for the lacuna that the fundamental concept of reality represents in the series of categories" (Cohen, 1883, 26). 
In Cohen's reading of Kant, the transcendental principles are not deduced or discovered $a$ priori, but are found through a historical investigation of the development of the 'mathematical science of nature'. The 'apriority' of such principles lies exclusively in their 'transcendental' role, in the fact that they are not a byproduct of the laws of nature, but a condition that such laws have to satisfy to be recognized as such (Cohen, 1883 , sec. $8,6 \mathrm{ff}$.). ${ }^{5}$ Cohen's book provides an example (in hindsight, a not very convincing one) of applying what he labeled the 'transcendental method' (for Cohen as an interpreter of Kant, see the still unsurpassed Edel, 1988). Cohen wanted to show that the 'infinitesimal method' was discovered in response to a problem that Kant tried to distill into the category of reality and the principle of Anticipations of Perception. Thus, the difficulty of Das Princip der Infinitesimal-Methode is, one might say, partly the result of the 'hermeneutic' circularity of the argument: Kant's second principle is the presupposition of the historical investigation, and the historical investigation serves to reveal the real meaning of the principle.

According to Cohen, in fact, "the character of the infinitesimal magnitude as intensive magnitude is the necessary mediation" (Cohen, 1883, 15) between these two tasks, "since the critical meaning of reality is preferentially expressed in the infinitesimal intensity" (Cohen, 1883, 14). Cohen admits that Kant did not explicitly point out this connection, as one might have hoped (even if several pieces of textual evidence are provided; see below section 3.3), though this is only due to the fact "that the identity of the intensive and the infinitesimal was a general assumption in the time of Kant" (Cohen, 1883, 14). Making this assumption explicit could shed light on the problem that the introduction of infinitesimally small quantities was trying to solve. The foundation of the concept of the 'differential', which mathematics could not provide, can then be found in the critique of knowledge.

Cohen was convinced that the notion of the 'infinitesimal' did not emerge historically from the investigation of algebraic (infinite series) or geometrical (tangent and quadrature) problems, but rather in the context of 'mechanics', i.e., the emerging modern science of motion. He tirelessly reasserts that "[t] he mechanical motif of the concept of the differential" (Cohen, 1883, 21, 52), was "pivotal [ausschlaggebend]" "for the discovery of the concept of the differential" (Cohen, 1883, 21). According to Cohen, it is "precisely this new motif" that explains why "neither the geometers nor the analysts could manage what they had in their hands" (Cohen, 1883, 21) . On the contrary, "in defining this concept, Leibniz and Newton met with Galileo and Kepler, whose genius was dedicated precisely to the other motif," namely, the mechanical motif (Cohen, 1883). Thus it is "from the source and from the beginning of the mechanical problems" that "in the last instance the concept of the differential ultimately emerged" (Cohen, 1883, 22-22). And it is precisely in this mechanical meaning that "the differential corresponds to a fundamental concept of pure thought, the category of reality. And the discoverers of the calculus insist clearly on this final motif, too" (Cohen, 1883, 23).

Cohen's hypothesis is not without some intuitive plausibility. In a varying motion, where velocity should be thought of as having a different value from moment to moment, it should be possible to determine the velocity of a moving body in every indivisible instant. In the case of a uniform motion, "velocity can still initially be represented in its sensible primitiveness [in sinnlicher Naivetät]" as a change of position in time (Cohen, 1883, 49). On the contrary, "in the case of acceleration [...] one cannot avoid assuming infinitesimals from the beginning" (Cohen, 1883 49). The velocity has to be defined in the instant where no change of position occurs. This is what Galileo sensed, but was not able to fully express conceptually:

\footnotetext{
${ }^{5}$ A proper understanding of Cohen's concept of the a priori would require a separate investigation. In particular I do not agree with the claim that the Marburg school defended a regulative conception of the $a$ priori (Friedman, 1999).
} 
The first prototypical example of force is the law of a falling body. And thereby we recognize the method of the infinitesimally small quantities as the creative fundamental concept [...] On the other hand it could appear odd that Galileo already used the instrument that he needed, even if others after him had introduced it. [...] [However,] in spite of the geniality of Galileo's presentation, he was not able to fully cover the conceptual gap that separates the indivisible from the differential. His shortcomings are testified to by the expressions that Galileo accumulates in order to distinguish the emerging motion from the finished one. L'Impeto, il talento, l'energia, il momento del discendert ${ }^{6}$; il momento o la propensione al $\operatorname{motc}^{7}$; quali furono gl'impeti ... tali ... $i$ gradi ${ }^{8}$ Through these expressions the tendency [to move] is sensibly described but not conceptually determined. Leibniz seems to have grasped this lack of clarity by using the expression 'embryonal impetuosity' in the very interesting passage in which he touches on his relationship with Galileo (cf. GM, 4:159). Indeed, it is the infinitesimal acceleration not the embryo, but the productive reality (Cohen, 1883, 51).

In finding the laws of a falling body, Galileo had to define the tendency of a body to continue with the same velocity and direction, even in an instant in which there is no motion (no change of position); Galileo saw the need for a new conceptual tool, which he tentatively defined as 'the impetus, energy, ability, the moment of descent'. According to Cohen, Galileo is expressing in a confused way the "desideratum of this epoch-making thought" (Cohen, 1883), of the concept that should have been introduced to make 'motion' the object of the mathematical science of nature. Already at this point, in the law of free fall, "the infinitesimal principle is revealed as creative," and for this reason we regard it "as a fundamental mechanical concept [mechanischen Grundbegriff]" (Cohen, 1883, 47). In some sense, "before the concept of the differential was secured, its effectiveness and validity were latent" in Galileo's 'new' science of motion (Cohen, $1883,51)$.

In this mechanical sense, "the work of the infinitely small has already been found by the man who established and secured the first great foundation for their valorization" (Cohen, 1883), that is, Galileo: "Galileo presupposes the infinitely small in the sense of productive reality in his definition and demonstration of the concept of accelerative force" (Cohen, 1883, 45). A falling body, dropped from a position of rest, has to pass through 'infinite degrees of slowness', so that a finite momentum might be considered as an accumulation of momenta, which are assumed to be infinitely small with respect to ordinary motion (Dühring, 1873, 30ff.).

In Cohen's parlance, then, 'motion'- the idealized object of a mathematical science of nature is not simply 'given', but is 'produced' by 'conceptual' means (an expression deprived of every psychologically subjectivist meaning), starting from what the motion is not, namely, rest. Rest is, however, not absolutely different from motion; it is an infinitely slow motion. As is well knownand we can only touch on this topic here - this relative form of negation (Cohen, 1883, 35-37), which for Cohen can be traced back to the ancient distinction between general relativityo $>$ uk $>$ 'on and general relativitymh >'on (see Cohen, 1878), will later play a central role in the development of his philosophy (cf. Poma, 1997, for more details).

\subsection{Leibniz as the Discoverer of the Infinitesimal Calculus}

Cohen's allusion to the relationship between Galileo and Leibniz is essential to his argument. His interpretative strategy is particularly clear in his analysis of Leibniz's contribution to the discovery of the calculus. Cohen maintains that, even in Leibniz's case, the first formulation of the concept of the 'differential' through algebra and geometry is only the premise for the

\footnotetext{
${ }^{6}$ Galilei, 1855- 13:174.

${ }^{7}$ Galilei, 1855- 13:176.

${ }^{8}$ Galilei, 1855- 13:177.
} 
solution of the authentic problem: "If we want to understand the concept of the differential in the principled meaning that it had for its discoverers, we must direct our attention to the interest from which this concept has emerged" (Cohen, 1883, 54). Also in the case of Leibniz the "third motif [the mechanical motif after the geometrical and arithmetic ones]" is the one we regard as "the decisive motif itself for the discovery of the concept of the differential" (Cohen, 1883, 47). Cohen speaks of a "prevalent [vornehmliche] tendency towards mechanics," of a "converging in this of all operations with the differential" into mechanics (Cohen, 1883, 63). The significance of the infinitesimal "was first appreciated in the purest form through the discovery of geometry. But the roots of this valorization are nevertheless in its realizing value, thus in mechanics" (Cohen, 1883, 63).

Cohen could emphasize that "[j] ust as Galileo, Leibniz also described velocity as intensio." He distinguishes diffusio actionis in motu vel actionis extensio from the intensio ejusdem actionis, the striving towards some determinate motion (Cohen, 1883, 71, cf. GM, 6:355). In particular, Cohen could refer to the passages where Leibniz explicitly claims that motion, if regarded as mere geometrical change of position in a certain time span, does not have any physical reality per se; there is nothing real in motion except that momentary something (momentaneum illud) - the tendency to continue with the same velocity - which Leibniz describes as "something beyond extension, in fact, something prior to extension" (alicquid praeter extensionem, imo extensione prius) (Cohen, 1883, 71; cf. GM, 6:235). In Cohen's reading, Leibniz introduced the notion of the 'differential' as a means for conceptually grasping the momentaneum illud that is beyond extension (Cohen, 1883, 71).

In the context of this unilateral appreciation of Leibniz's mechanical applications of the calculus, Cohen gives particular importance to the passages in which Leibniz considered ordinary motion that extends through time as the result of the summation of an infinite number of infinitely small increments: the dead force is the element or differential of motion, and the integration of dead force with respect to time gives rise to ordinary motion. According to Cohen, this shows the precise 'philosophical' meaning of the 'infinitesimal method': ordinary motion, "the finite inasmuch as it aspires to have objective validity" (Cohen, 1883, 144), is not simply 'given'; to become a legitimate object of scientific experience, it should be regarded as a 'result', "as the sum of those infinitesimal intensive realities, as a definite integral," the infinite repetition of elementary, infinitely small elements (Cohen, 1883, 144).

Translating this into his own peculiar lingo, Cohen can then claim that "if one defines the differential as reality," say $d v$ at the very beginning of the motion while it remains infinitely small or elementary, then $\int v d v$, "the integral means the real as an object" (Cohen, 1883, 144), as a motion extending through time. The production of finite continuous quantities appears as the sum of infinitesimal quantities. In turn, such elementary increments arise from an infinite number of lower-order elements, which are 'infinitely small in comparison with the preceding', and so on (cf. GM, 6:238).

If $d x$ is the difference between two minimally different values of $x$ - since $d x$ is not always constant - $d d x$ is a difference of differences, and further proceeds to $d d d x$ or $d^{3} x$ etc. $d^{e} x$. (cf. GM 7:222-3). As expected, Cohen emphasized that in the differentials of higher orders the concept of the differential reveals again its mechanical meaning (Cohen, 1883, 73); if the first differential is speed, the infinitesimal distance traveled by a body in an instant, the second is acceleration, an infinitely small change in a body's speed (Cohen, 1883, 74).

Cohen was of course aware that Leibniz, on many occasions, deemed the infinitesimal a modus loquendi, a facon de parler, since, properly speaking, there are no 'infinitesimal magnitudes' (GM) 5:289). However, Cohen tried to downplay this undeniable tendency by claiming that it was the consequence of Leibniz's "own lack of confidence" in light of the "prejudices of his time" (Cohen, 1883 88). For this reason, he tried to defend his calculus "with the old methods" (Cohen, 1883 
88). Even if "Leibniz had emphasized the productive force of his concept enough," he nevertheless "did not want to dispense with the advantage of presenting his procedure to the public opinion as equivalent to the method of limits" (Cohen, 1883, 78). As a result, Leibniz insisted that he was able to reformulate any proof involving infinitesimals into a proof in the style of Archimedes cf., eg., GM, 1:322: "as if the differential had nothing more definite to say than the limit of the differences" (Cohen, 1883, 78).

Paradoxically, Cohen's reading of Leibniz is particularly interesting from our point of view because in many respects it is untenable. Leibniz discovered the calculus in the context of the theory of number sequences, then extended it to the sequences of ordinates and abscissas (Bos, 1974, 1986). It was only later that Leibniz applied his calculus to mechanical problems. Moreover, Leibniz never defended an 'accumulative' conception of the continuum as a sum of infinitesimally small quantities, an approach he took in his writings on physics only as a manner of speaking (Rutherford, 2008). In marked contrast, he saw the continuum as an inexhaustible possibility of division, where the whole is given prior to the possible parts; and thus for Leibniz there is neither the infinitesimally small nor the infinitely large (Breger, 1986). This is probably Leibniz's most important contribution to the topic, and Cohen completely misunderstood it.

However, Cohen's attempt to force Leibniz into his conceptual scheme makes features of the latter more evident. Cohen wanted to show that Leibniz discovered the calculus to conceptually establish the momentaneum illud, which confers physical reality to geometric motion, which otherwise would be a mere relative change of position. According to Cohen, this is the same problem Kant cryptically expressed in his second principle, by establishing a relation between reality, intensive magnitude, and the mathematical concept of the 'moment'. Through this connection one can see, at the same time, "the meaning of the category of reality and the secret of the concept of the differential" (Cohen, 1883, 28).

\subsection{The Second Edition of Kants Theorie der Erfahrung}

Cohen's second revised and augmented 1885 edition of his Kants Theorie der Erfahrung (Cohen, 1885) incorporated many of the innovations he had developed in the previous decade. It was actually an entirely new book, in which Cohen, in an often precarious equilibrium between textual analysis and systematic reconstruction, attempted to rebuild the entire apparatus of Kant's philosophy in stronger idealistic terms. Cohen did not just insist on the central role of the synthetic principles (in opposition to the categories) as the condition of the possibility of mathematical the science of nature (as epitomized in Newton's Principia). He also made the more hazardous claim that "the arrangement of the principles could become more transparent, after it was discovered that the principle of the intensive magnitude is the key principle" (Cohen, 1885, XII).

Cohen thought he had showed that it was only by reconstructing the history of the infinitesimal method that one could grasp the problem that formed, at least in nuce, the basis of the Anticipations of Perception. To provide evidence for this claim, Cohen referred his readers to several passages in which Kant seems to move in this direction. In formulating the principle, Kant argues that "if one regards this reality as a cause," then "one calls the degree of reality as a cause a "moment', e.g., the moment of gravity" (B, 210), that is, the moment $d v$ of acceleration of a free-falling body. According to Cohen, in Kant's use of the concept of a 'moment', one can glimpse "the mechanical motif, which ultimately produced intensive magnitude as differential" (Cohen, 1885, 436).

In the second "Analogy of Experience" Kant returns to the concept of 'moment', affirming that change is "possible only through a continuous action of causality, which, insofar as it is uniform, is called a moment" $(\mathrm{B}, 254)$. An alteration "does not consist of these moments, but it is generated through them as their effect" $(\bar{B}, 254)$. In these passages, although "Kant does not 
refer anywhere to inertia" (Cohen, 1885, 465), according to Cohen, he probably uses the term 'moment' to indicate the tendency of a body to continue in rectilinear and uniform motion, if the acceleration were to become constant (Cohen, 1885, 464-465). The finite velocity acquired by a body can then be described as the effect of the successive accumulation of such momenta.

Referring to a 1789/90 Reflexion on the moment of speed at the beginning of free fall (Ref. 67, Ak. 14:497), which Stadler had already mentioned, Cohen emphasizes (Cohen, 1883, 111; Cohen, 1885, 430) that Kant defines the moment of velocity (or better, the moment of acceleration) "not as velocity itself," but as "the tendency of bodies to communicate a certain velocity". Even more significantly, Kant defined it not as "extensive, but as an intensive magnitude," (Ref. 67, Ak. 14:497). Thus the finite 'motion' is generated, starting from rest, as the sum of the infinitesimally small motions; if the moment of velocity was zero, ${ }^{9}$ "through their summation there would not emerge any finite magnitudes" (Ref. 67, Ak. 14:497). Therefore, as Kant put it in another Reflexion from the late seventies, the "production of reality has a moment of the qvanti extensivi which is a sort of element: differentiale" (Refl. 5582, Ak. 18:240). Just as different moments produce different degrees of velocity, Kant continues, so do different impressions produce different degrees of sensation (Refl. 5582, Ak. 18:240).

These are precisely the passages Stadler had quoted in his 1883 monograph (see section 3), where he tried to show that it was incorrect to identify the intensive magnitude Kant attributes to speed with the intensive magnitude he attributes to reality. Cohen, as Stadler had sensed, unabashedly embraced the opposite interpretation, and saw in this Reflexion one of the key passages to support his interpretation: "Thus we see that the intensive is considered here as a type of magnitude in itself, and that it is applied to those concepts that determine the law of fall as the prototype natural law" (Cohen, 1885, 432).

Cohen nevertheless acknowledged his debt to Stadler. It was Stadler who led him to completely rethink his own interpretation of the Anticipations of Perception. In Cohen's words, Stadler "rightly opposes the continuity of sensation as an a priori determination" (Cohen, 1885, 437). Not only is there no 'pure transcendental foundation' for the continuity of sensation, but Stadler also demonstrated that empirical studies on the psychology of sensation are even less capable of demonstrating a posteriori that sensation grows in a continuous way. However, Stadler "only looks for the pure transcendental foundation he is missing in the sensation" (Cohen, 1885, 437). He did not realize that "the "pure transcendental foundation"" he was looking for cannot be found "in the sensation, but only for the sensation" (Cohen, 1885, 437).

In other words, Stadler still thought that psychophysics offered the conceptual framework to understand the problem Kant was facing. According to Cohen, however, this framework was inadequate for understanding Kant's concept of the "intensive": "the so-called intensity of sensation must absolutely be distinct from the intensive magnitude or reality of sensation" (Cohen, 1883 156). Elsas, in his review of Stadler's 1883 book, seems to clearly point out where Stadler was no longer in accordance with the emerging 'Marburg' approach to Kant. Stadler considered motion as the stimulus of sensation (Elsas, 1885, 146); according to Elsas, however - even if there is some textual evidence to support this psychological interpretation - the central point is different: transcendental philosophy should try to explain what makes general mechanics a science and thus what makes 'motion' a legitimate object of scientific inquiry: "The task is to explain the fact of science, the fact of general mechanics" (Elsas, 1885, 146). The relation between motion and sensation is philosophically irrelevant.

\footnotetext{
${ }^{9}$ Cohen interprets this passage as a critique of Euler's conception of the differentials as zero (Cohen, 1883 111).
} 


\section{Hatchet Jobs: Cohen's Book and Its Reviewers}

Cohen's attempt to interpret the 'differential' as 'intensive magnitude', or even as 'intensive reality', immediately prompted negative reactions in the mathematical community. At the end of 1883, Georg Cantor sent a review of Cohen's book to the Deutsche Literaturzeitung (Cantor, 1884). Cantor recognized Cohen's book as a "clever and learned work" (Cantor, 1884, 267). However, he dissented strongly from Cohen's insistence on the 'reality' of the infinitesimals. Whereas every rational or irrational number is continually well-defined, and is in some sense part of the 'being', in contrast, "the so-called infinitely small numbers or differentials do not belong to the sphere of the being," but rather to those of the "non-being, changing, becoming" (Cantor, 1884, 267): a quantity is not infinitely small, but rather becomes infinitely small (decreases without bound toward zero). They cannot be conceived of "as proper magnitudes, as it happens here, even if only in the sense of the intensive or protensive magnitudes" (Cantor, 1884, 267). According to Cantor, this was also Leibniz's opinion; in particular, though, it was Gauss who considered the differential as a "variable finite" (Cantor, 1884, 267).

Cohen was actually pleased that Cantor bothered to review the book and he wrote him a letter expressing his gratitude (Sieg, 1994, 143). On 21 February 1884, he wrote to Kurd Lasswitz10. "some days ago I received from Cohen a nice [letter] about my review, with some counter-arguments that I do not really understand" (Cantor to Lasswitz, 21 Feb. 1884; Eccarius, 1985, Doc. 7, 19). Lasswitz's reply has not been preserved. However, it seems plausible that he tried to defend Cohen's point of view. In fact, in a letter dated 9 March 1884, Cantor replied with the following: "for the time being, I maintain my objection that the differential cannot be conceived as an autonomous magnitude" (Cantor to Lasswitz, 21 Feb. 1884; Eccarius, 1985, Doc. $8,20)$. According to Cantor, the differential is only a sign that a certain finite magnitude is conceived of as a variable that decreases indefinitely in such a way as to fall below any given number, i.e., that it has zero as a limit. For this reason, "the meaning of the differential lies in the differential-quotient, which is nothing but the limit of the difference-quotient" (Cantor to Lasswitz, 21 Feb. 1884; Eccarius, 1985. Doc. 8, 20). This issue, as we shall see, returns again and again in discussions of Cohen's book.

Cantor's letter is a good example of the standard reaction of the mathematical community: in his criticism of the 'method of limits', Cohen seemed to have been completely unaware of the process of 'rigorization' of the analysis developed in nineteenth-century mathematics. This process - so goes the well-known story - starting with Augustin Cauchy in about 1820 (the mean value theorem), was completed by 'the great triumvirate': Karl Weierstrass (in his lectures at the University of Berlin), Richard Dedekind (Dedekind, 1872), and Cantor himself (Cantor, 1872 1879). In particular, Weierstrass's 'Epsilontik' (so called for the usage of $\epsilon$ and $\delta$ as variable names) would become the standard approach to analysis (cf. e.g., Bottazzini, 1986). Even if other non-mainstream approaches were present in the mathematical literature at the time (cf. e.g., Stolz, 1883 see Ehrlich, 2006 and, with reference to Cohen, Mormann and Katz,2013), it is not evident in the early reception of Cohen's book. One might read Sigmund Günther's review (a mathematician working on Moritz Cantor's history of mathematics) as a good example of the customary reaction of the mathematically-trained reader of Das Princip der Infinitesimal-Methode.

In fairness, though, it must be emphasized that Cohen's mathematician critics were probably not sufficiently comfortable with his terminology to grasp the philosophical point he was trying to make. In particular, they seem to have completely missed that the meaning of the word 'real', referring to infinitesimals, was connected with Kant's category of 'reality', which cannot

\footnotetext{
${ }^{10}$ Cantor was at that time in correspondence with Kurd Lasswitz regarding the latter's paper on Giordano Bruno (Lasswitz, 1884).
} 
be equated with existence, even in the mathematical sense of the expression. Thus, Cohen's sympathizers, such as Elsas, took some pains while reviewing the book to 'translate' Cohen's philosophical jargon "for the non-philosophically-trained mathematicians and physicists" (Elsas, 1884, 560).

Elsas resorted to none other than Bernhard Riemann's claim: "True elementary laws can operate only in the infinitely small," so that "the derivation of laws for extended bodies and time periods requires their integration" (Riemann, 1869,4). However, Cohen had higher philosophical ambitions for identifying the 'differential' with the 'intensive reality' than the somewhat banal claim that physics makes use of (partial or ordinary) differential equations.

However, other philosophically sophisticated mathematicians like Gottlob Frege simply could make no sense of Cohen's jargon. In his review (Frege, 1885), Frege listed a series of propositions from Cohen's book, complaining about the absence of precision, logical consistency and clarity in Cohen's presentation. Moreover, although agreeing with Cohen's anti-psychologism (Frege, 1885 329), Frege condemned the use of historical investigations in the theory of knowledge. According to Frege, "from the logical point of view, the historical starting point appears as something accidental" (Frege, 1885, 326, see also Frege, 1891 for a similar point).. For Frege, even if the notion of the differential has emerged from geometrical and mechanical problems, the logical foundation of the infinitesimal calculus is purely arithmetical (Frege, 1891, 326), and is ultimately based on the concept of a limit (Frege, 1891, 329). In arithmetic, the difference between intensive and extensive magnitudes has no place.

However, even among his own acolytes, Cohen's book was not well-received. Stadler, as we have seen, had already attempted to refute ante litteram Cohen's interpretation, and apparently would never agree with it in subsequent years, despite their continuing friendship (Cohen, 1910 see also Cohen, 2015 for their late correspondence). The most critical among his students was surely Ferdinand August Müller (see above section 3). In his Das Problem der Continuität im Mathematik und Mechanik (Müller, 1886), he offered a polite yet severe criticism (he would be much less polite in private correspondence; see below in this section) of Cohen's endeavor.

Cohen, according to Müller, has "committed the same mistake that psycho-physics fell into" (Müller, 1886, 96n.). He attributed this mistake "to something which, like the differential, is not a real object [...], a magnitude, indeed an intensive magnitude" (Müller, 1886, 96n.). This was, according to Müller, a complete misunderstanding of the method of limits (Müller, 1886, 96n.). Cohen seems to have been convinced that the 'differential' $d x$ of the variable $x$ has a meaning isolated from the differential quotient $\frac{d y}{d x}$. But, according to Müller, $d x$ is not an ultimate indivisible part of a continuum, a quantity smaller than any finite quantity and still not zero. It is only "the sign for a content without an extent [Umfang]," since $d x$ is actually equal to zero; without the relationship to $d y$ in the differential quotient, it has no meaning (Müller, 1886, 99-100).

This criticism of Cohen was also raised by much more sympathetic readers, like Lasswitz. In fact, Lasswitz's correspondence with Cantor had the unintentional consequence of attracting Lasswitz's attention to Cohen's historical reconstruction. In 1885 he wrote a positive review of Cohen's book. Although he complained about "the difficulties of the subject matter and obscure writing style" (Lasswitz, 1885a, 494), Lasswitz accepted Cohen's main claim that "the infinitesimal concept of the differential" has "its historical origins in mechanical problems" (Lasswitz, 1885a 499). Lasswitz was ready to recognize "the infinitesimal reality as a highly effective thought-mean," even if one still "doubts the relationship with [the symbol] $d x$ [as used by] the mathematicians" (Lasswitz, 1885a, 502).

Lasswitz in fact wondered whether the intensive reality "can really be identified with the mathematical differential or rather with the functional connection with the differential of a second variable," that is, in the relation between $d x$ and $d y$ in the differential quotient (Lasswitz, 1885a 502). This is particularly evident in the case of the differentials of higher order (as Cantor 
pointed out to Lasswitz in their correspondence). In the $d^{2} x, d^{3} x$, etc., there is nothing qualitative that can distinguish them from one another: If $x$ is a length, then $d^{2} x, d^{3} x$, etc., are also lengths smaller than any given lengths. Only in the differential quotient, when set in relation to other infinitesimally small quantities, do differentials assume a qualitative meaning. Thus if $d x: d t$ is a velocity, then $d^{2} y: d t^{2}$ is an acceleration; if $d y: d x$ is the slope of a tangent, then $d^{2} y: d x^{2}$ is the curvature, etc. (Lasswitz, 1885a, 502).

Cohen was of course pleased by Lasswitz's review. As he admitted in a letter of 7 April 1886, he had not been "spoiled" by positive reviews (Cohen to Lasswitz, 7 Apr. 1886; Holzhey, 1986, 2:166). Concerning Lasswitz's criticisms, he confessed that he did not have the text of Lasswitz's review within reach to provide a proper answer. However, Cohen made clear that he did not want to contradict the mainstream presentation of calculus: "the terminology of the Diff.-Calculus is correct and absolutely compatible with the intensive reality" (Cohen to Lasswitz, 7 Apr. 1886; Holzhey, 1986, 2:166). He suggested that in a second edition of Das Princip der Infinitesimal-Methode he would have shown "how he thought it was possible to express the elementary Diff.-Calculus and its rules in this language," that is, in the language of the "intensive reality' (Cohen to Lasswitz, 7 Apr. 1886; Holzhey, 1986, 2:166).

Lasswitz's positive review, however, did not seem sufficient to improve the chances of Cohen's book. The young Edmund Husserl, writing to Franz Brentano on 29 December 1886, was baffled that Lasswitz could give an "enthusiastic reception" to the "nonsensical profundity" or "profound nonsense" of Cohen's prose (Husserl to Brentano, 29 Dec. 1886; Husserl, 1994-, 5). Unsurprisingly, the Marburg community soon became aware that a more accessible presentation of Cohen's philosophy of the infinitesimal method was needed.

Elsas pointed this out in writing to Lasswitz at the beginning of 1887, when he thanked him for the review (Lasswitz, 1887) of his book (Elsas, 1886). One could have taken into account the hostility coming from outside Marburg; but Müller's attacks, "who some years ago was part of our restricted circle" came as a wake-up call (Elsas to Lasswitz, 7 Jan. 1887; Holzhey, 1986 2:171). Elsas confessed to Lasswitz "that Cohen's exposition could be made transparent only through strenuous intellectual work" (Elsas to Lasswitz, 7 Jan. 1887; Holzhey, 1986, 2:172). It was not easy "to translate the scholastic language of philosophers into the poorer language of physicists" (Elsas to Lasswitz, 7 Jan. 1887; Holzhey, 1986, 2:171). Elsas was ready to act as an interpreter, despite the fact that, because it lay on the boundary between the two disciplines, this work of mediation was not appreciated by his colleagues in the physics department. However, he confessed that "often I myself am not sure if Cohen really means and says what I read off or hear from his elliptic remarks" (Elsas to Lasswitz, 7 Jan. 1887; Holzhey, 1986, 2:172).

A month later, on 8 February 1887, in another letter to Lasswitz, Elsas again expressed his uneasiness about Cohen's work, adopting an ambiguous attitude that can be found again and again among members of the Marburg school. Elsas felt entitled to defend, explain and translate Cohen's book for the world outside Marburg; at the same time, he was uncomfortable with the obscurity and paradoxicality of Cohen's foundation for the infinitesimal analysis. Elsas admitted that "in Cohen I am missing a concise formulation that could substitute for Kant's failed 2nd principle" (Elsas to Lasswitz, 8 Feb. 1887; Holzhey, 1986, 2:173). Most of all, Elsas conceded to Lasswitz that the relation between Cohen's use of $d x$ and that of the mathematicians was unclear: "Cohen should not have used the math. sign". Elsas agreed with Lasswitz that $d x$ has no meaning without the relation to a $d y$ : "But what remains of the 'principle of connection' between $d x$ and $d y, x$ and $y$ ? You feel that there is something missing here. I cannot help you, because I have the same feeling and I'm myself looking for something that fills the gap. Maybe there is nothing of the sort" (Elsas to Lasswitz, 8 Feb. 1887; Holzhey, 1986, Br. 12, 2:182).

In his 1886 book on psychophysics (Elsas, 1886), Elsas had tried to 'fill the gap' by emphasizing that the 'physical' significance of the notion of 'velocity', regarded as intensive magnitude, could 
not be completely expressed in its mathematical 'translation' as the differential quotient $\frac{d s}{d t}$ (Elsas, 1886, 68). However, as we have just seen, in private correspondence he was clearly not entirely satisfied with this explanation. Lasswitz, in a long 1888 paper, "Das Problem der Continuität" (Lasswitz, 1888a), tried to put in more comprehensible terms how this 'physical' meaning should be interpreted. In order to make the scientific concept of motion possible, Lasswitz explains, it is necessary to express the tendency of a body in motion to continue with the same velocity, a tendency that can be defined even in the durationless instant, i.e., even when there is no change of position, and thus no motion. Without this dynamical element, motion would not be a physical object. This element beyond extension therefore represents the "reality" of motion, what distinguishes physical motion from mere geometrical change of position.

For this reason, according to Lasswitz, "the category of reality" (Kategorie der Realität) corresponds to what he preferred to call the "means of thinking of variability" (Denkmittel der Variabilität) (Lasswitz, 1888a, 29). In Lasswitz's words, "without the means of thinking of variability the flying arrow would be at rest at every point of its path" (Lasswitz, 1888a, 29), that is, the very definition of physical motion would be impossible. However, he also notices that "the connection of the principle of the intensive magnitude and the category of reality with the infinitesimal method indeed only becomes clear via the relations to the concept of function" (Lasswitz, 1888a, 29). Although Lasswitz defended Cohen from Müller's criticisms, he pointed out that "the constitutive, realizing character" can be found not "in the differential as such, but only in the differential that is the subject of a differential equation" (Lasswitz, 1888a, 30), $d y=f^{\prime}(x) d x$. Lasswitz's remarks were intended to be an explanation of Cohen's point of view: "the umbrage that mathematicians have taken at Cohen's interpretation of the $d x$ should be eliminated through the distinction that we have tried to make" (Lasswitz, 1888a, 30).

After receiving Lasswitz's paper, Müller was clearly still unconvinced. He replied to Lasswitz on 26 October 1887, in an amicable tone (Müller to Lasswitz, 26 Oct. 1887; Holzhey, 1986, Br. $13 ; 172)$, but he did not refrain from calling the very notion of 'intensive reality' "one of the most monstrous births in the entire history of philosophy" (Müller to Lasswitz, 26 Oct. 1887; Holzhey, 1986, Br. 13; 172). Such a harsh judgment from an ex-student might suggest that personal issues were at stake. However, it is undeniable that those who were ready to concede the 'honors of war' to Cohen's book were forced to extract the valid parts of his contribution, explaining away the more questionable ones, such as the identification of the 'differential' $d x$ as such with the 'intensive reality'.

As we will see, however, Cohen always insisted on considering the 'differential' as such, in isolation from the differential quotient, as a specific philosophical problem encoded in the category, or later, the 'judgment' of reality. However, this was clearly not accepted at face value by even Cohen's sympathizers. Natorp, the thinker closest to Cohen, had already insisted in an 1891 paper "Quantität und Qualität in Begriff, Urteil und gegenständlicher Erkenntnis" (Natorp, 1891a) that the central concept in calculus is the 'differential quotient'; despite Cohen's insistence, "the 'differential' does not need any particular foundation" (Natorp, 1891a, 153).

\section{Kurd Lasswitz and the Urbanization of the Cohenian Province ${ }^{11}$}

During the 1880s, a group of scholars began to gather around Cohen's Marburg chair. Natorp was surely the most successful, as he had already published several respected papers and monographs (Natorp, 1884, 1887, 1888). However, outside of the Marburg school, the previously

\footnotetext{
${ }^{11}$ The title of this section alludes to Jürgen Habermas' laudatio for Hans Georg Gadamer: 'Die Urbanisierung der Heideggerschen Provinz' (Habermas, 1979).
} 
mentioned Stadler from Zurich and the Gymnasiallehrer Lasswitz from Gotha were also engaged in fruitful dialogue with Cohen. Stadler did not follow Cohen after his 1883 'idealistic' turn, but Lasswitz made an enormous, though largely forgotten, effort to implement Cohen's interpretation of the infinitesimal calculus in his own historical work. In this way, Lasswitz 'translated' Cohen's insight into a language more accessible to those unfamiliar with his often obscure jargon, but Lasswitz did this by setting aside relevant features of Cohen's approach.

In the late eighties and early nineties, Lasswitz made several contributions to the history of early modern science in the Vierteljahrsschrift für wissenschaftliche Philosophie, in which the influence of Cohen is expressly recognized. The first part of an 1888 paper on Galileo's theory of matter (Lasswitz, 1888b) marks one of the first examples of how Lasswitz regarded Cohen's work on the infinitesimal calculus.

\subsection{From Galileo to Huygens: Lasswitz's History of Atomism}

Lasswitz approached his historical work in a Neo-Kantian manner, by searching for the "means of thinking or principles that in the general sense of the critique of knowledge are a condition of scientific thought" (Lasswitz, 1888b, 460); this was only possible by searching "in the content of science as it is given in experience". Galileo's "foundation of a new science," and in particular his scientific treatment of the concept of motion, is a particularly significant example of this (Lasswitz, 1888b, 460).

"The main difficulties" in the definition of the concept of motion, Lasswitz argues, is that "[m]otion presupposes the course of time" (Lasswitz, 1888b, 461), namely, it is a change of position in time. Thus, in every instant where there is no change of position, there is in fact no motion. There must therefore be something that defines motion as a physical object in the durationless instant as well: there must be "something in the instant of time that differentiates the body in motion from one at rest, a reality of motion that cannot be eliminated when we abstract from time" (Lasswitz, 1888b 461). This can be found "in the dynamical capacity of producing effects of the body in motion" (Lasswitz, 1888b, 461). The body in motion, considered in the instant, is essentially different from the body at rest, "though not through an extensive magnitude, which is eliminated by the abstraction, but rather through an intensive one" (Lasswitz, 1888b, 461).

At this point, according to Lasswitz, a new conceptual problem arises. It is necessary to "ground this tendency to produce effects in a mathematical concept and subject it to knowledge" (Lasswitz, 1888b, 462). Lasswitz explicitly refers to Cohen's monographs (Cohen, 1883, 1885) "for the connection between the concept of continuity and of intensive magnitude, as well as for the relation to Kant's thought" (Lasswitz, 1888b, 462n.).

According to Lasswitz, the great achievement of Galileo's concept of 'moment' was precisely that it tried to provide an expression for this conceptual element ${ }^{12}$ In 'statics', when bodies are in equilibrium, "there is already the moment as a tendency to fall" (Lasswitz, 1888b, 470). The moment is the tendency, the impetus to move downward; bodies are trying to descend but are mutually hindered, and hence have not achieved any actual motion yet. The general cause of equilibrium is the equality of moments, not the equality of absolute weights. Galileo discovered that "the concept of velocity is here already, even if only in a virtual sense" (Lasswitz, 1888b 470).

Galileo was then able to transform the 'static' concept of moment into a 'dynamic' one by postulating that one can define velocity in every arbitrarily (beliebig klein) small part of time. In this way, a pure rational element is substituted for a sensible and intuitive one, since motion in arbitrary parts of time cannot be perceived, but only postulated. It is assumed that the "quality

\footnotetext{
${ }^{12}$ On Galileo's concept of moment, see the still-useful Galluzzi, 1979
} 
of velocity is not eliminated with the quantity of time," but remains as what "characterizes the process of motion" as such (Lasswitz, 1888b, 473). In this way, according to Lasswitz, "by means of the conceptual characterization of the intensity of motion," Galilei was able to explain how "in the unit of time the tendency [to motion] also still remains," even if no change of position, i.e., no motion, can be defined (Lasswitz, 1888b, 473).

The "full impact" (Lasswitz, 1888b, 473) of Galileo's approach can, however, be appreciated in his definition of the law of the uniformly accelerated motion. By modeling his dynamical concept of 'moments of velocity' upon the static concept of 'moments of weight', Galileo was able to understand acceleration; the finite 'moment' of a body can be regarded as composite and aggregate of infinitely many momenta, with a direct causal relationship between the accumulation of the momenta and the acceleration of the motion. The moment of a body in the act of percussion is nothing but a composite and aggregate of infinitely many momenta. "The gap between being and non-being is bridged, since the becoming is regarded as growing out of the infinitesimal increments" (Lasswitz, 1888b, 473).

In the second part of the paper, published a year later (Lasswitz, 1889), Lasswitz tried to show that the Denkmittel der Variabilität, which was applied successfully to Zeiterfüllung, "the filling of time', cannot be expected to apply with equal success to the Raumerfüllung, the "filling of space" (Lasswitz, 1889). Galileo's attempt to solve the problem of the rarefaction and condensation of matter by resorting to the rota Aristotelis - that is, by assuming that a body could be composed of an infinite number of unquantifiable atoms, just as the total speed of a body is the sum of an infinite number of indivisibles of speed - was bound to fail (Palmerino, 2001). According to Lasswitz, if Galileo's attempt was pursued systematically, it would lead to a dynamical conception of matter, like those later formulated by Kenelm Digby, Roger Joseph Boscovich and, of course, Kant. Lasswitz insisted, however, that "the question concerning the continuity of matter and attractive and repulsive forces, even if Kant thought that he could not avoid it, has become irrelevant" (Lasswitz, 1889, 21). In Lasswitz's view, "the world is no less continuous, because it consists of atoms; only the world process has to be continuous" (Lasswitz, 1890, 381). It is the causal connection between atoms that must be considered continuous, not matter itself.

According to Lasswitz, the dynamical concept of matter à la Kant-the explanation of a certain degree of the 'filling of space' through a repulsive force balanced by an opposite attractive one - is incapable of explaining the passage from 'dynamics' to 'mechanics'. It cannot explain how "the parts of space act as wholes," that is, it cannot answer "the question of the individualization of matter" (Lasswitz, 1885b, 144). This problem "cannot be solved through the concept of intensive reality, but only via the concept of substance" (Lasswitz, 1889, 144). Thus there is a sort of 'latent atomism' even in the dynamical theories.

Lasswitz explicitly went in a different direction from Stadler and Cohen. However, according to Lasswitz, there is no contrast between 'atomism and criticism' (Lasswitz, 1878). Atoms are not 'things', but epistemological conditions introduced to make mechanics possible. Elsas had objected that the notion of 'point mass' was sufficient to ground mechanics without the necessity of introducing extended atoms. The material point is, so to speak, a "bodily differential and has all properties [of a body]" . The only difference between material points is that we attach "different mass coefficients" to them (Elsas to Lasswitz, 8 February 1887; Holzhey, 1986, 2:176177). However, Lasswitz did not seem to take this quite convincing objection seriously, perhaps because in principle the mass/volume density of a point particle would approach infinity.

The results of these and others historical investigations were incorporated into Lasswitz's masterpiece, his monumental Geschichte der Atomistik (which is still worth reading), published in two volumes in 1890 (Lasswitz, 1890) and covering nearly a thousand pages. Here Lasswitz explains with great clarity what he learned from Cohen: a major result of modern science was the possibility of conceptually determining "[t]his autonomous and intensive reality of motion" 
(Lasswitz, 1890, 2:6), which distinguished the phoromonomical/geometrical motion, a mere change of position in time, from that of real physical motion. This was "the precondition of the discovery of the differential calculus" (Lasswitz, 1890, 2:7).

However, applying this conceptual tool to matter itself could not achieve the hoped-for result, and instead led down a blind alley. The problem in fact lay elsewhere: if the 'Denkmittel' of variability defines the reality of motion in the instant, the identity of the subject of motion through time should be realized only through the application of another 'Denkmittel', that of substance. Lasswitz's philosophical 'hero' was thus Christiaan Huygens, the founder of 'kinetic atomism' and the first to clearly separate these two problems. On the other hand, according to Lasswitz, the confusion of these two means of thinking inevitably leads to Leibniz's substantialization of force, epitomized in the notion of a primitive force or monad, a metaphysical entity that tries to entail both the continuous change of states and the permanence of substance (Lasswitz, 1890 2:580; cf. Willmann, 2012 for more details).

\subsection{Cohen's Reaction to Lasswitz and the Concept of Field}

In his review of the Geschichte der Atomistik (Natorp, 1891b), Natorp pointed out that there seems to be no reason why 'variability' should be related to time, while 'substantiality' is related to the extension of space. However, Lasswitz had provided perhaps the most convincing attempt "to further explain Cohen's path-breaking book about the principle of the infinitesimal method" (Elsas, 1891, 301). But as Cohen immediately recognized, Lasswitz's 'explanation' was also an 'urbanization'. It made the most paradoxical aspects of Cohen's philosophy of the 'infinitesimal' more palatable, but also watered down their philosophical implications ${ }^{13}$ Cohen did not fully agree with Lasswitz's choice of terminology, as he explains in a letter from July 1891: "I know that your 'variability' wants to and can lead to an effective improvement, but I could not truly convince myself of the accuracy of its formulation" (Holzhey, 1986, Cohen to Lasswitz, 27 July 1891, Br. 21, 2:202-203).

In 1896-the year Cassirer arrived in Marburg - Cohen published a long "Einleitung mit kritischem Nachtrag" to the 5th edition of Lange's Geschichte des Materialismus (Cohen, 1896). The paragraphs on Galileo seem to confirm that Lasswitz had grasped the spirit of Cohen's 1883 book (Cohen, 1896, XXVIIff.). Cohen in fact expressed appreciation for Lasswitz's attempts to present his interpretation "in his excellent work Die Geschichte der Atomistik" (Cohen, 1896 XLVII). However, he considered Lasswitz's presentation as a "weakening," where the "agreement with which he has supported my theory, has at the same time compromised it again" (Cohen, 1896, XLVII). Cohen believed that in Lasswitz's work, "the concept of reality [is reduced] to a concept of relation of variability" (Cohen, 1896, XLVII). However, according to Cohen, "[i]n the infinitesimal one does not find merely the origin of the magnitude, but at the same time the being itself, the real". For this reason, Cohen insists, "for the logical legitimation of the concept of the differential I have highlighted the fundamental concept of reality" (Cohen, 1896, XLVII). The proper 'being' of physical quantities is at stake, not simply their 'variability'.

Thus, Cohen considered Lasswitz's separation between 'substantiality' and 'variability'between the discreetness that defines the subject of motion and the continuity of motion and change - to be unacceptable. In the "Kritischer Nachtrag", the first work in which Cohen attempted a more systematic confrontation with nineteenth-century physics (Hertz, Planck, etc.), Cohen seems to suggest that the development of the concept of a 'field' had made Lasswitz's distinction unnecessary. As is well known, in the 1830s, Faraday, the "pathfinder of our times"

\footnotetext{
${ }^{13}$ It is interesting to note that in this form, Cohen's conception of the infinitesimal calculus could even be accepted by some working mathematicians, such as Giulio Vivanti (1894) or by Max Simon (1898).
} 
(Cohen, 1896, XXIX), substituted the action at a distance, which prevailed among continental theorists, with the action of an intervening medium. He introduced the concept of 'lines of force' to represent the disposition of electric and magnetic forces in space.

According to Cohen, in Faraday's treatment of "the problem of the acting-at-a-distance forces" (Cohen, 1896, XLV) and his "[r] eluctance towards atomism" (Cohen, 1896, XXIX), the old physics of particles has been substituted by a new physics of fields. "The fundamental hypothesis of the Faraday-Maxwell Theory" (Cohen, 1896, XXX), in Cohen's view, means "the overcoming of the problem of matter by the problem of force" (Cohen, 1896, XXIX), where matter appears as an epiphenomenon of the field. Here we observe the "greatest transformation in the concept of matter and the transformation of matter into force and energy," in which Cohen could celebrate "the victory of idealism" (Cohen, 1896, XXIX).

Even if one is skeptical of his triumphalist rhetoric, one must acknowledge that Cohen was relatively up to date. It was only a few years earlier, in $1887 / 88$, that Heinrich Hertz had produced and detected electromagnetic waves for the first time, and then adopted Maxwell's theory of electricity, which most German physicists had ignored. Cohen explicitly refers (Cohen, 1896 XXX) to Hertz's "Introduction" to a collection of papers on electricity published in the early nineties (Hertz, 1892). Cohen was also quick to recognize that the field concept would have led to an 'Infinitesimal-Theorie' (Planck, 1887, 244-245), as Planck called it - a turn of phrase Cohen could not fail to appreciate - that is, to a localization of energy conservation (Cohen, 1896 XLVIII).

Cohen's reference to the field concept was brief but not isolated. In 1902, a philosophical Preisaufgabe was announced, in which candidates were asked to explicitly deal with Faraday's relation to Boscovich's theory of matter (Sieg, 1994, 501). The prize went to the 'cand. phil' Otto Buek (1873-1956), a German-Russian scholar born and raised in St. Petersburg, who had landed at Marburg for his doctorate (Sieg, 1994, 207ff.). Responding to the Preisaufgabe, Buek developed Cohen's insights about the field concept and the Maxwell-Faraday theory of electricity, in what would later become his dissertation, "Die Atomistik und Faradays Begriff der Materie", to appear in the Archiv für Geschichte der Philosophie in 1905 as a long article (published in 1905 as Separatdruck).

In reconstructing the origin of the field concept in Faraday's work, Buek homed in on the fact that Faraday - who in the 1930s had employed the concept of lines of force merely to represent the alignment of polarized particles - later tried to overcome the problem of explaining the mode of transmission of the force between contiguous particles by assuming that matter will be continuous throughout, thus eliminating the difference between particles and any intervening space (Faraday, 1844). Historically, Buek attempted to trace Faraday's treatment of material particles as nothing but point-centers of converging lines of force back to Boscovich's dynamic theory of point-atomism, as it was developed in the mid-eighteenth century ${ }^{14}$

Even if Buek was careful not to burden his historical reconstruction with philosophical debate internal to Neo-Kantianism, one of his polemical targets was clearly Lasswitz's 'critical atomism' Lasswitz's separation of the subject of motion from motion itself "has its origin in an incorrect abstraction" : "The atom alone should represent the substance, while motion is submitted exclusively to means of thinking of variability" (Buek, 1904, 161). Lasswitz had summarized Cohen's connection between intensity, reality and the infinitesimal in his 'Denkmittel der Variabilität', and applied it to motion alone; however, he had hypostatized in the extended atom the subject of motion as what remains identical in the process of change. Huygens's 'kinetic atomism' was the historical realization of this epistemological model. Faraday's critique of atomism could be

\footnotetext{
${ }^{14}$ Boscovich's influence on Faraday is usually downplayed in recent literature cf. Spencer, 1967
} 
presented by Buek as a historical example of an alternative model, in which Cohen's connection between intensity, reality and the infinitesimal could find universal application: here, "the determination fixed in the point is what is actually real" (Buek, 1904, 108).

\section{The Young Cassirer's 'Dialectical' Confrontation with Cohen's Interpretation of the Infinitesimal Calculus}

When Buek, one of Cohen's most beloved students (Sieg, 1994, 501, n. 74), was preparing his dissertation, the Marburg school was perhaps at the beginning of its golden age, thanks primarily to Natorp's academic engagement there. Natorp became ordinarius in Marburg in 1893 (Sieg, 1994 174); in the following years, he acted as the editor of the Philosophische Monatshefte and of the Archiv für systematische Philosophie, and was considered as a possible editor of the "KantStudien," which had been founded at the end of the century (Ferrari, 1988, 91). Moreover, during this time, in addition to his monumental monograph on Plato (Natorp, 1903), he published a series of papers on the foundation of mathematics, which showed a grasp of recent developments in the field that was clearly superior to Cohen's (Natorp, 1900, 1901, 1902a).

The Preisaufgaben (see above on ??) became a powerful tool whereby doctoral students developed some of the core insights of the school through their often sophisticated historical investigations. "Once again," Natorp wrote to one of the recipients, Albert Görland ${ }^{15}$ on 21 November 1902, "we got an excellent Preisarbeit from Mr. Bueck [sic] about Faraday; the 4th in a row ([18]96, [18]98, [19]00, [19]02, you [Görland], Cassirer, De Portu, Bueck" (Natorp to Görland, 21 Nov. 1902; Holzhey, 1986, Br. 72, 2:302). The Preisarbeiten were expanded into dissertations and monographs of some value. In 1899, Görland published his dissertation as the second chapter of a larger work on Aristotle and mathematics (Görland, 1899). In November 1901, Cassirer had finished transforming his thesis on Descartes into the first chapter of his Leibniz monograph Leibniz' System in seinen wissenschaftlichen Grundlagen (Cassirer, 1902). Buek had finished though not yet submitted his Faraday-Arbeit by the end of 1903 (Natorp to Görland, 26 May 1904; Holzhey, 1986, Br. 85, 2:235); Enrico Maria De Portu, a mathematician by training, submitted his work on Galileo in 1904, which became the first part of a monograph (Portu, 1904) (Natorp to Görland, 26 May 1904; Holzhey, 1986, Br. 85, 2:235).

\subsection{Cassirer on Leibniz and the Infinitesimal Calculus}

It was the young Cassirer ${ }^{16}$ who immediately emerged as the most promising of this group of students. Cassirer's book on Leibniz (Cassirer, 1902), for all its limitations, can be considered one of the classics of the so-called Leibniz-Renaissance at the turn of the century, together with the books of Bertrand Russell (Russell, 1900) and Louis Couturat (Couturat, 1901). Cassirer dedicated the book to "his teacher" Cohen, "with sincere respect and gratitude". Both stylistically and terminologically, the book is profoundly tied to the work of Cohen and the Marburg school.

As Natorp wrote to Görland on 13 January 1902, Cassirer's book "was for a good part prepared by Cohen and, if I may say it, by myself," even if "[a] part of the theses are new outside of Marburg" (Natorp to Görland, 13 Jan. 1902; Holzhey, 1986, Br. 59, 2:271). However, "I find great maturity and autonomy and also a lot is new for me" (Natorp to Görland, 13 Jan. 1902; Holzhey, 1986, Br. 59, 2:271). Cassirer's reliance on the 'Cohenschen Methode' was the explicit reason Cassirer was unable to obtain the Habilitation in Berlin. Natorp was surprised, however, that even Wilhelm Dilthey (one of the three full professors in the commission) was unable to see "that Cassirer, in

\footnotetext{
${ }^{15}$ For a not exactly flattering portrait of Görland see Cassirer Bondy, 1981. 144.

${ }^{16}$ The most thorough enquiry into the young Cassirer and the Marburg school remains Ferrari, 1988
} 
spite of the Cohenian terminology, is sui juris" (Natorp to Görland, 13 Jan. 1902; Holzhey, 1986 Br. 59, 2:271) ${ }^{17}$

That Cassirer was 'sui juris' emerges from, among other things, the fact that he was careful not to rehash Cohen's view on Leibniz's philosophical justification of the infinitesimal calculus ${ }^{18}$ Cassirer never mentions the notion of 'intensive magnitude' or the category of reality in the long chapter dedicated to the infinitesimal calculus. This sort of language emerges only in the chapter on Leibniz's concept of 'force', which "for Leibniz [...] is synonymous with reality [Realität]" (Cassirer, 1902, 288).

After all, the young Cassirer's approach confirms that Lasswitz's reading of Cohen's 1883 book was the only one that could make sense of the latter's approach. In distinguishing the phoronomic from the dynamical concept of motion, the concept of the infinitesimal becomes indispensable; it is a condition for the possibility of the natural sciences. Motion, writes Cassirer, paraphrasing Leibniz, ${ }^{19}$ "is a continuous arising and disappearing of determinations in succession"; therefore, it also lacks the consistency of identity that is demanded as a logical presupposition of reality (Cassirer, 1902, 291). The reality of motion that was lost when motion was only a geometrical change of position "is obtained again by fixing the overall process in the single temporal element [im einheitlichen Zeitmoment]" (Cassirer, 1902, 291).

The determinacy of reality in the instant "cannot signify a single sensible presence, but rather a conceptual fixation [...] this demand is satisfied through the Leibnizian concept of force" (Cassirer, 1902, 287); more precisely, in the concept of 'derivative force', "the differential of motion" (Cassirer, 1902, 291). In this sense, one can affirm "that the thought that produced the concept of force meant nothing to us other than that logical function that showed itself in action [wirksam erwies] in the principles of the infinitesimal calculus" (Cassirer, 1902, 297). According to Cassirer, one can say that the "fundamental idea of the infinitesimal" produced, in its application to space and time, "the content as intensive magnitude" (Cassirer, 1902, 303).

Cassirer, however, did not accept Lasswitz's criticism that Leibniz "substantialized the force as the cause of motion" (Cassirer, 1902, 336). In supporting Huygens' atomism against Leibniz, according to Cassirer, Lasswitz had misunderstood "the proper meaning of the concept of substance developed by Leibniz" (Cassirer, 1902, 336-337). Lasswitz's critique is the consequence of his "own system," because he considers "substantiality" and "variability" "as two different means of thinking" (Cassirer, 1902, 337).

In contrast to Lasswitz, Cassirer tried to show that in Leibniz, "the problem of matter [...] is posited in an immediately clear connection with the problem of the infinitesimal calculus" ; a finite mass is considered as a "diffusion of quality," is represented as a "relationship between a differential and its integral," as the integral $\int d \rho$ of the matter density $d \rho$ (Cassirer, 1902 342-343). Similarly, Leibniz considers "the emergence of a finite 'quantity of motion' from the elementary impulse" and "the developement of the element of velocity from continuous repetition of acceleration (as element of second orders)," as an "expression of integration as a continuous summation of infinitesimal moments".

These passages, so clearly 'Cohenian' in flavor, should not mislead. Cassirer explicitly emphasized that in this context, Leibniz's intuitive parlance must not be confused with a rigorous foundation of the infinitesimal calculus. Mathematically, Leibniz's strategy is precisely the oppo-

\footnotetext{
${ }^{17}$ For the failure of Cassirer to obtain the habilitation in Strassburg, Natorp points out that Cassirer's Jewish origins were explicitly mentioned (Natorp to Görland, 13 Jan. 1902; Holzhey, 1986 Br. 59, 2:271).

${ }^{18}$ For this reason, I think one should be cautious using 'Cassirer's early work as a cipher for reading Cohen', as in Moynahan, 2003, 38. Here I follow Ferrari, 1988, who rightly insists on the difference between Cassirer and Cohen.

${ }^{19}$ GM 6:235..
} 
site: not the 'production' of the finite as a summation of infinitesimal elements, but "the thought of the conservation of the logical value of the quantity in the elimination of its intuitive being" (Cassirer, 1902, 173). It is precisely "this second direction that prevails in considering the pure mathematical derivation of the differential, whereas the first, which is prior philosophically, finds its final expression in Leibniz's mechanics" (Cassirer, 1902, 173). Thus, despite the undeniable Marburg rhetoric that permeates Cassirer's book, the difference from Cohen's position remains very significant.

In contrast to Cohen, Cassirer asserted that the foundation of the infinitesimal calculus resides precisely in the concept of the 'limit': "the zero of the limit," he pointed out, "indeed has a positive meaning" (Cassirer, 1902, 174). In the "passage to the limit' it is shown how "the magnitude must first disappear for the sensible apprehension, so that we can grasp its determination in its purity" (Cassirer, 1902, 174): The $d x$ is zero in its extensive quantity, but in its conceptual, qualitative aspects it is fully determined through all the relationships that defined the $x$ (Cassirer, 1902, 174). For this reason, however, according to Cassirer, the concept of the 'differential quotient' is the fundamental one, not the 'differential': "the differential quotient is the mathematical expression of the autonomy and the originality of the relation with respect to the element from which the relation is obtained" (Cassirer, 1902,177).

Cassirer's reading of Leibniz's famous definition of continuity-Datis ordinatis etiam quaesita sunt ordinat ${ }^{20}$ ('If the data are ordered, the quaesita must be ordered also') - is, in its unilaterality, revealing:

While initially continuity meant for [Leibniz] the origin of a variable considered in methodological isolation, now he refers explicitly to the reciprocal dependence of variables. The concept of function is indeed everywhere already implicitly presupposed in the preceding remarks: the conceptual relations of data and quaesita are mathematically completely represented through the connection between the independent variables and the function. This is the meaning of the principle which states that, when the difference in the 'given' is diminished under an arbitrary value, it must be possible that the difference in the 'results' also becomes smaller than every quantity, however small: [Leibniz's] formula [...] [Datis ordinatis etiam quaesita sunt ordinata], as one can see, paraphrases the usual definition of the continuity of a function, according to which $\left|x^{\prime}-x\right|<\epsilon$ becomes $\left|f\left(x^{\prime}\right)-f(x)\right|<\delta$. If one considers this connection, one comes to the remarkable result that in the general definition of continuity the definition of function is already entailed (Cassirer, 1902, 239).

Thus Cassirer even credited Leibniz for having anticipated the Epsilontik! Cassirer's reading, from a historical point of view, is of course just as implausible as Cohen's, but for the opposite reason: Leibniz did not possess the concept of 'function' and reasoned in terms of variables ranging over a sequence of values (Bos, 1986).

The crucial point, however, lies elsewhere. Cassirer's treatment of the continuity problem in his Leibniz monograph dissents significantly from Cohen's position, and here it is not hard to glimpse the embryo of Cassirer's mature philosophy. At the beginning of the passage just quoted, the disagreement with Cohen seems to become nearly explicit. Even if there is no direct reference to Cohen, it is hard not to read the opposition between the 'Ursprung of a variable in isolation' and the 'reciprocal relation of variables' as Cassirer's veiled attempt to distance himself from one of the major features of the philosophy of his Doktorvater.

In May 1902, the first volume of Cohen's 'system of philosophy', the Logik der reinen Erkenntnis (Cohen, 1902), appeared from the publisher Bruno Cassirer (Cassirer's cousin). As is well known, in the Logik the concept of Ursprung or 'origin' plays the central role. It would be impossible

$20 \overline{\mathrm{GM}}, 6: 29$. 
to spell out the details of this complex and obscure book here (for more on the topic I suggest the classical monographs of Holzhey, 1986 and Poma, 1997). However, it is clear that Cohen insisted on the precise line of thought that Cassirer criticized, modeling the concept of 'origin' on the relationship between an isolated $d x$ and its integral $x$ (Cohen, 1902, 124ff.), conceived again as the summation of infinitesimal elements. Cohen was careful to distinguish the historical 'discovery' from the mathematical 'justification' of the calculus (Cohen, 1902, 135), as Cassirer had also done. However, he also explicitly rejected the priority of the 'differential quotient' over the 'differential' (Cohen, 1902, 182-183). For Cohen, the notion of 'function' is derivative with respect to the productive force of the 'differential' considered in its isolation. The problem is in fact the origin of $x$ itself and not its relationship to $y$ (Cohen, 1902, 280ff.).

The dissatisfaction with Cohen's systematic work was far from isolated. In June 1902, Hans Vaihinger thanked Natorp for his decision to review Cohen's work in the Kant-Studien ${ }^{21}$ It was only a few months later, however, that Natorp wrote to Görland that he had renounced the project after realizing that Cohen felt he was being misunderstood (Natorp to Görland 21 November 1902; Holzhey, 1986, Br. 72, 2:301-302). In the review, Natorp complained that one cannot regard the quality "as an autonomous, pre-mathematical knowledge" (Natorp, 1902b 15-16) independent from quantity. The concept of the infinitesimal - as Natorp wrote in another unpublished commentary on Cohen's logic - lies in the fact that in the vanishing of the quantity, the quality of the law is preserved; the 'origin' of the quantity has to be sought precisely in this qualitative unit. However, this can only be expressed in terms of a functional relationship between quantitative determinations: "To completely isolate the infinitesimal from the quantity and to establish it without regards to the latter, as a matter of fact, does not work" (Natorp, 1902-1909 $53)$.

\subsection{Defending Cohen: The Cassirer-Nelson Controversy}

Thus, both Cassirer and Natorp seem to have fully acknowledged the necessity of accepting Cohen's presentation of the calculus with reservations. In an attempt to extrapolate the philosophical spirit of Cohen's 1883 book without endorsing its most controversial aspects, it is curious that they de facto embraced the very same elements of the critiques that Cohen's approach had received outside of Marburg. Bertrand Russell, in The Principles of Mathematics (Russell, 1903) remarked that aside from the "historical excellence" of Cohen's book, he was "led astray by very important mathematical errors;" in particular, he failed to notice that "The $d x$ and $d y$ of a differential are nothing in themselves, and $d y / d x$ is not a fraction" (Russell, 1903, 325; but see Russell, 1900, 88 for a more benevolent reading). Even if Russell's remarks cast a negative light on Cohen's work, we have already seen similar remarks in the private correspondence and published writings of many in Cohen's own circle.

When, in 1904, the 23-year-old Göttinger philosopher Leonard Nelson wrote a long and devastating review of Cohen's Logik der reinen Erkenntnis (Nelson, 1905), the 'Marburgers' were probably not completely surprised. As Nelson pointed out with ruthless sarcasm, "with his views about differential, series and functions Cohen located himself completely outside of that domain of science that we today call mathematics" (Nelson, 1905, 621). According to Nelson, "the works of Cauchy, Weierstrass and their pupils" had shown that "the so-called infinitely small from a mathematical point of view and this [the analysis] never have anything to do with actually existing infinitely small magnitudes, understood in some sort of mystical sense" (Nelson, 1905, 617). In contrast, Cohen attributed to the infinitesimal not just "autonomous meaning and existence," but he treated it "as an origin- and production-principle for the finite" (Nelson, 1905, 619). Coming

${ }^{21}$ Natorp Nachlass Hs 831/1066, cit. in Ferrari, 1988 107n. 130. 
from Nelson, who was highly esteemed among Göttinger mathematicians like Felix Klein and David Hilbert, this review had serious consequences for the image of the Marburg school. Hilbert even took pains to borrow the book from Nelson: "it did not take him long," as Nelson wrote to Gerhard Hessenberg, "to declare the book a satirical piece [Bierzeitung]" (cit. in Peckhaus, 1990 192).

"In the Gött[ingische] Gel[ehrte] Anz[eigen]," Natorp wrote to Görland on 25 September 1905, there is "a little 'double murder': my Platon a[nd] Cohen's Logic are killed one after the other" (Natorp to Görland, 25 Set. 1905; Holzhey, 1986, Br. 98; 2:352). Natorp was not particularly upset by the review of his book (Goedeckemeyer, 1905); however, Nelson's review of the Logik, which immediately followed, clearly had a different effect: "Nelson put forward against Cohen mathematics and Kant. There, he must defend himself" (Natorp to Görland, 25 Set. 1905; Holzhey, 1986, Br. 98; 2:352).

It was actually Cassirer who, in 1905, wrote an unusually harsh reply to Nelson (Cassirer, 1906b), which symbolically opened the series 'Philosophische Arbeiten', edited by Cohen and Natorp ${ }^{22}$ as though he had to defend the honor of the Marburg school as a whole ${ }^{23}$ Cassirer pointed out that Nelson was criticizing a caricature. Of course, Cohen regarded "the infinitesimal not as thing, but as a condition" (Cassirer, 1906b, 32), that is, a condition of the possibility of the mathematical determination of motion. Cassirer's reply was indignant, and was followed by a long and unpleasant controversy with the other members of Nelson's group (Cassirer, 1907c 1909 vs. Grelling, 1907, Hessenberg, 1908, Meyerhof, 1907).

Cohen was grateful to Cassirer for having taken his side (Cohen to Cassirer, 22 Nov. 1905, ECN, 17, Doc. 19, 209ff.). However, Cassirer's defense of Cohen, when concerning the vexed question of Cohen's conception of the 'infinitesimal', was vague enough to conceal a much greater difference of perspective between him and his teacher. The "Nelson-Battle" — as Cohen ironically called it (Cohen to Cassirer, 2 Jun. 1906, ECN, 17, Doc. 27, 229) 24 - once again revealed the delicate equilibrium between staying loyal to the school and avoiding some of Cohen's clearly unacceptable claims.

In 1906, in the first volume of the Der kritische Idealismus und die Philosophie des 'gesunden Menschenverstandes' (Cassirer, 1906b), on the one hand, Cassirer seems to agree with Cohen that Galileo's concept of 'moment' was the first example of the infinitesimal: "the concept of infinity, which did not manage to escape internal difficulties when it was attributed to spatial continuity, was clarified and fixed for the first time through the concept of velocity" (Cassirer, 1906b, 330). On the other hand, he draws a completely different conclusion. Cassirer's formulation of the problem clarified that "neither the differential of space, nor even that of time can show the way" (Cassirer, 1906b, 330). Instead he argued that, "historically and logically, the concept of the differential quotient was the point of departure" (Cassirer, 1906b, 330). Thus, it is not $d y$ and $d x$ taken alone, but rather the "functional equation" within which these assume their significance that "offers the most secure and 'substantial' base that scientific thought can give for the constitution of magnitude" (Cassirer, 1906b, 330-331).

This was of course the same point Cassirer wanted to emphasize in Leibniz's work. In the edition of Leibniz's major writings he edited with Arthur Buchenau in 1904 (Leibniz, 1904-1906), Cassirer chose as a representative of Leibniz's position toward the infinitesimal calculus the 1701 writing Justification du Calcul des infinitésimales par celui de l'Algèbre ordinaire (GM, 4:104-6). Here, Leibniz imagines a figure in which the lengths of two straight lines $c$ and $e$ diminish steadily

\footnotetext{
${ }^{22}$ For a complete list of the publications in this series see Holzhey, 1986 1:384-385.

${ }^{23}$ The brief "Zur Einführung" which opens the series testifies well to this 'sense of belonging' to a philosophical community (Cassirer, 1906b I-III)

${ }^{24}$ The pun refers of course to the Admiral Lord Nelson and the Battle of Trafalgar.
} 
and finally disappear; $c$ and $e$, however, are not absolutely nothing, since the ratio of $c$ to $e$ will remain constant. As Cassirer insisted in the annotations to this text, what emerges here is the centrality of the "functional relationship" between magnitudes, rather than the magnitudes themselves (Cassirer's footnote in Leibniz, 1904-1906, 1:102). As Cassirer put it in the second 1907 volume of Das Erkenntnisproblem, here one can see "the originality and the initial paradox of the infinitesimal calculus" (Cassirer, 1907a, 71).

In 1906, Cassirer registered the Erkenntissproblem as Habilitationschrift at the FriedrichWilhelms-Universität in Berlin ${ }^{25}$ Cassirer held the Probevorlesung on 26 July 1906. This time Dilthey did not want to enter the annals of history as the man who had rejected Cassirer, and thus Cassirer obtained the longed-for venia legendi - despite the opposition of Alois Riehl and Carl Stumpf (cf. Gawronsky, 1949, 12 and Cassirer Bondy, 1981, 101). The revealing title of Cassirer's lecture, "Substanzbegriff und Funktionsbegriff" (Cassirer, 1906c), suggests that his remarks about the infinitesimal calculus can be seen as just one example of his larger project, namely, describing the historical process of the prevailing concept of function over that of substance, as was systematized in his classical 1910 monograph (Cassirer, 1910).

\section{The Marburg Divide: Gawronsky, Cassirer and Natorp on the Interpretation of the Calculus}

Cassirer probably did not consider his approach to be in opposition to Cohen's. A month before his 'Probevorlesung' on 28 June 1906, Cassirer wrote to Natorp that he could not completely understand the latter's disagreement with Cohen: "between both of you there is at least an agreement concerning the logical priority of quality over quantity. This is the key issue" (Cassirer to Natorp, 28 June 1906; Holzhey, 1986, Br. 100, 2:350).

In summarizing to Natorp the results of his recently finished paper on Kant's philosophy of mathematics (Cassirer, 1907b), Cassirer insisted that even by introducing the natural numbers and creating the number series, "the qualitative moment of the 'order' is the only fundamental and decisive moment; it precedes the 'plurality' and makes it possible" (Cassirer to Natorp, 28 June 1906; Holzhey, 1986, Br. 100, 2:350-351). So one can proceed further by introducing rational numbers, irrational numbers and by defining the number continuum without ever abandoning the definition of number as series: "even in the pure arithm. domain one can abstract from the quantitative 'multiplicity from unities'. After all, Cohen does not want to claim anything more than this" (Cassirer to Natorp, 28 June 1906; Holzhey, 1986, Br. 100, 2:351).

Cassirer's latter claim is of course quite doubtful. In particular, Natorp's concern was far from specious. After having read Cassirer's dispute with the neo-Friesians, Natorp confessed to Görland: "Cohen's treatment of the concept of the differential dismisses too quickly the fact that the $d x$ is nothing in itself, it is completely dependent from the presence of a differentiable function, from the presence of a limit value (convergent series) etc" (Natorp to Görland 27 July 1907; Holzhey, 1986, Br. 108, 2:361). Although Natorp did not believe that Cohen's point of view depended on this, he had to admit that "some [of Cohen's] formulations are without doubt incautious" (Natorp to Görland 27 July 1907; Holzhey, 1986, Br. 108, 2:361).

The irenic picture Cassirer painted was indeed not the one perceived in Marburg. As the young Nicolai Hartmann — who had just finished his dissertation (N. Hartmann, 1908) —reveals in a letter to his friend Heinz Heimsoeth on 9 July 1908, the relationship between Cohen and Natorp was deteriorating. Natorp criticized Cohen in detail in public, for hours, even though

\footnotetext{
${ }^{25}$ Today's Humboldt-Universität zu Berlin. Archiv der Humboldt-Universität zu Berlin, Philosophische Fakultät 1228: Acta der König. Friedrich-Wilhelms-Universität.
} 
according to Hartmann, many people were on Cohen's side: "The spokesman thereby is a certain Mr. Gawronsky, a really highly gifted man and a born mathematcian" (Hartmann to Heimseoth, 9 Jul. 1908 F. Hartmann and R. Heimsoeth, 1978, 29). Hartmann was referring to the Russian émigré Dimitry Gawronsky, who was ten years younger than Cassirer and his close friend (Cassirer Bondy, 1981, 121 and 299-300; Sieg, 1994, 486). As Hartmann wrote to Heimsoeth on 5 October 1909, "Gawronsky will soon submit his dissertation and he is 'working for his examination', as he says, even if no one really grasps why he should still be working on that" (Hartmann to Heimseoth, 9 Jul. 1908 F. Hartmann and R. Heimsoeth, 1978, 29).

Gawronsky's dissertation, Das Urteil der Realität und seine mathematischen Voraussetzungen, was apparently poorly received by the Marburg mathematicians, and in particular by Kurt Hensel (Fraenkel, 1967, 109). It was published a year later (Gawronsky, 1910) and it represents a significant example of a quite different attitude towards Cohen's controversial approach to the 'infinitesimal' within the Marburg school. Gawronsky attempted to provide a sort of 'update' of the Logik der reinen Erkenntnis, which, instead of 'urbanizing' Cohen's approach to the 'infinitesimals', tried to justify it in light of more recent, even if less mainstream, developments in mathematics.

Upon cursory reading, Gawronsky seems to embrace Cassirer's interpretation of Leibniz's foundation of the calculus. In Leibniz's dictum Datis ordinatis etiam quaesita sunt ordinata, one can see how he "provides the foundation of the functional continuity" (Gawronsky, 1910, 35 ), so that the "continuity of the function precedes the continuity of magnitude" (Gawronsky, 1910, 35). The change of the data corresponds to a change in the quaesita, and this relationship maintains its meaning even when the difference between data and quaesita vanishes. However, Gawronsky's agreement with Cassirer's reading was meant to show that Leibniz was not radical enough: Leibniz "relies for his deduction of the differential calculus on the concept of the function of the differential quotient [...] and for this reason the proper meaning of the concept of the differential does not become sufficiently apparent" (Gawronsky, 1910, 91).

Historically, in Gawronsky's view, Newton's presentation seems more radical philosophically. Newton introduced the concept of a 'moment' $o \dot{x}$, an infinitesimal increment acquired by a finite quantity $x$ that varies in time. The 'moments' of the fluent quantities $\dot{x}$ are the infinitely small additions by which those quantities increase during each infinitely small interval of time: "one sees that here the function does not come to the fore yet" (Gawronsky, 1910, 83-84). Of course, Newton did not neglect the concept of function and differential quotient; rather, "Newton separated the problem of the differential and of the differential quotient, and considered both" (Gawronsky, 1910, 85).

This is one of the central issues Gawronsky insists upon throughout his book, in more or less explicit disagreement with Cassirer and Natorp: "the interests of the differential and those of the differential quotient should be clearly differentiated from one another" (Gawronsky, 1910). The differential in itself has no particular meaning and it raises a problem because, "inside the function one cannot separate the single differentials" (Gawronsky, 1910, 104). For Gawronsky, however, this conception is philosophically unsatisfying: " $d x$ and $d y$ are regarded as increments of magnitudes. The magnitude that is conceived as increasing must be presupposed" (Gawronsky, 1910, 82). A question therefore arises: "where do they come from, who made them? One cannot consider them as simply given" (Gawronsky, 1910, 82). For this reason, according to Gawronsky, "the concept of function is not sufficiently primordial," since "it presupposes magnitudes that are connected in a functional way, without being able to be justified [legitimieren] through the demonstration of their legitimate [rechtmäßigen] origin" (Gawronsky, 1910, 82).

To justify the use of 'differentials' separate from the differential quotient, Gawronsky relies on the fact that an algebraic theory of infinitesimals was actually present in contemporary mathematics. He refers to alternative, non-Archimedean characterizations of continuity that were suggested by working mathematicians, and in particular Giuseppe Veronese (Veronese, 1897 
1908). Archimedes' axiom requires that, given two quantities $a$ and $b$, if $a$ is bigger than $b$, there is a number $n$ such that $n b>a$. If we drop this axiom, there is no multiple of $b$ that is bigger than $a$. This means that $b$ is infinitely small with respect to $a$ or, vice versa, that $a$ is infinitely large with respect to $b$. In this way, the geometrical continuum contains infinitely small and infinitely large segments; in Gawronksy's words, it "is produced, it is thought of as an infinite sum of infinitesimally small elements" (Gawronsky, 1910, 45).

Gawronsky's approach was indeed sophisticated. Via Veronese he introduced the Marburg community to a tradition going back to the work of Otto Stolz $(1883,1891)$ and Paul Du BoisReymond (1877), which Hans Hahn (1907) had recently shown was still fruitful (cf. Ehrlich, 2006 for more details). Unfortunately, Gawronsky's book is burdened by an apologetic agenda that probably rendered it unreadable outside Cohen's restricted group. At the same time, this is precisely why it constitutes an important document for understanding the moves of the orthodox 'Cohenian' front within the Marburg school.

In the introduction of his first big theoretical monograph, Die logischen Grundlagen der exakten Wissenschaften (Natorp, 1910) (the forward of which is dated March 1910), Natorp praised Gawronsky, "with his rich mathematical and physical knowledge" (Natorp, 1910, v), for having introduced the work of Veronese to the Marburg community. Natorp dedicated a detailed analysis of Veronese's work (see Mormann and Katz, 2013, sec. 4.5 for more details), insisting on a conception of the continuum as qualitative unity beyond infinite division into parts. However, he was far from using these results to 'save' Cohen, as Gawronsky had done.

Natorp of course defends Cohen against Russell's criticisms, emphasizing that they were based on "misunderstandings which are explainable through Cohen's difficult presentation" (Natorp, 1910, 222n.). Referring to the Nelson-Cassirer controversy, he also notices that, "[a]nother attack" was "appropriately" rebutted (Natorp, 1910, 222n.). However, this unavoidable defense does not conceal Natorp's uneasiness about Cohen's approach. Natorp took pains to emphasize that some "hyperbolic sounding" sentences could perhaps be understood and even, in some sense, endorsed, but could not be taken literally (Natorp, 1910, 218).

In Natorp's view, "the main difficulty in Cohen's treatment [...] lies in his apparently gruff rejection of the method of limits as the foundation of the infinitesimal method" (Natorp, 1910 220). For Natorp, the exact opposite is true: "the creative power of the infinitesimal procedure lies essentially in the passage to the limit" (Natorp, 1910, 220). Thus Natorp, in contrast to Gawronsky, fully embraced a textbook presentation of the calculus. The central concept is that the differential quotient $\frac{d y}{d x}$, which is defined as the limit of the quotient of corresponding finite increments of a variable; it is actually a new function, the derivative, and not at all a quotient in which $d y$ and $d x$ have any independent meaning (Natorp, 1910, 213ff.). In the same way, the integral is defined as the limit of a sum $\int_{a}^{b} y d x$, but $y d x$ does not have any actual significance like, say, a summand of a sum (Natorp, 1910, 221).

In some ways, one could say that "the path of a free falling body can be thought to be produced from instant to instant in infinitely many infinitely small velocity increments. The infinitesimal velocity appears then as the origin out of which the finite spaces successively flow" (Natorp, 1910, 215). However, for Natorp, this 'Cohenian' formulation was nothing more than a fac on de parler: "The real producer of the finite magnitude is not the 'infinitesimally small' magnitude," "but the law of the magnitude," which "can be thought of pictorially as concentrated into a point [...] or as spanned over a finite extension" (Natorp, 1910, 215). It is the same qualitative aspect of the 'law', which does not lose its significance in the transition to a quantitative zero, in the passage from the difference quotient to the differential quotient, and that it is recovered again in the reverse process of integration: "there is no other mystery here" (Natorp, 1910, 215). Cohen's notion of 'origin' finds its scientific counterpart in precisely the 'qualitative totality' that lies beyond the quantity. According to Natorp, "[a]fter all Cohen wanted to say this, even if his 
way of expressing it was not sufficiently immune from misunderstanding" (Natorp, 1910, 219).

Of course, Natorp must have been aware that this was not what Cohen wanted to say. As Cassirer pointed out in a long technical letter he sent to Natorp on 30 October 1909 (after having read the drafts of his book), Natorp "broadly speaking" deduces "the concept of continuity from the concept of law, from the persistence of the one and the same functional law" (Natorp to Cassirer, 30 Oct. 1909; Holzhey, 1986, Br. 120, 2:382). As Gawronsky's book shows, this was precisely the opposite of the orthodox Cohenian approach. It was clearly closer to Cassirer's point of view, who, however, had concerns about Natorp's "presentation of the infinitesimal procedure" (Natorp to Cassirer, 30 Oct. 1909; Holzhey, 1986, Br. 120, 2:382). The idea of the law's permanence, he pointed out, is necessary for a definition of continuity, but it is clearly not sufficient: "non-continuous functions and divergent series are also strictly lawful. Concerning these mathematical problems I still see some difficulties." (Natorp to Cassirer, 30 Oct. 1909; Holzhey, 1986, Br. 120, 2:382). Cassirer of course agreed with Natorp on the usual fundamental point, "the priority of "quality' over 'quantity"' (Natorp to Cassirer, 30 Oct. 1909; Holzhey, 1986 Br. 120, 2:384). For Cassirer, however, the infinitesimal calculus was significant, yet still just an example of this more general tendency.

The long letter to Natorp - which deserves a more detailed analysis - shows the technical knowledge Cassirer acquired in preparing his Substanzbegriff und Funktionsbegriff (Cassirer, 1910), which was finished in July 1910. By then, Cassirer had gone further than Natorp by questioning the centrality of the 'infinitesimal calculus' and of the very notion of 'origin'. For the first time, Cassirer even seems to cautiously but openly disagree with Cohen's approach to the topic: "Cohen's Logik der reinen Erkenntnis developed the notion of the origin in connection with the principles of the infinitesimal calculus" (Cassirer, 1910, 130-131). If, on the one hand, this is the first significant example of the transition from 'quantity' to 'quality', on the other, "[i]n spite of the protests of idealistic logic, the concept of the 'infinitely small' has continually led to the misunderstanding that magnitudes are not understood from their conceptual principle here, but rather compounded from their vanishing parts" (Cassirer, 1910, 131). In Cohen's work, the transition from "quantity" to 'quality' seems to be reduced to the attempt to find the "ultimate substantial constitution of magnitudes" (Cassirer, 1910, 131).

Cassirer seems to insinuate that Cohen failed to see that the true innovation of the "infinitesimal analysis" can only be understood when it is introduced, together with other types of "calculus," into "the more inclusive system" of the "'analysis of relations' in general" (Cassirer, 1910, 131). It is true that the analysis of the infinite is perhaps "the first and most distinctive example of the general perspective that leads back from the concept of magnitude to the concept of function, from the "quantity' to the "quality'" (Cassirer, 1910, 131). However, there are many other equally significant examples of this fundamental tendency in the development of mathematics and its application to physics: Möbius' barycentric calculus, Graßmann's 'Audehenungslere', Hamilton's quaternions theory, Maxwell's vector calculus, etc., can all be subsumed under "the same logical category" (Cassirer, 1910, 131).

The publication of Cassirer's monograph was a momentous event for the Marburg school; the book rapidly became the most respected and widely read scientific work outside of Marburg. Natorp did not seem to raise major objections, as inferred from Cassirer's postcard to him on 20 July 1910, in which Cassirer is pleased by the "full agreement" of their works (Cassirer to Natorp, 20 Jul. 1910; cit. in ECN, 17:271). Cohen's reaction was quite different. According to Gawronsky's later testimony, Cassirer's pages on the Logik were adjusted in the proofs because Cohen took umbrage at those remarks (Gawronsky, 1949,21). Although this claim is unsupported by further evidence (cf. ECN, 17:271), the anecdote is revealing of how Cassirer's remarks might have been perceived within the Marburg community.

On 24 August 1910, Cohen wrote a letter to Cassirer that Gawronksy later made famous, 
having cited part of it in his biographical notes introducing the Schilpp-Volume that was dedicated to Cassirer (Gawronsky, 1949, 21). The full original German has recently been made available, and the letter is worth citing at length:

I congratulate you and all members of our philosophical community on your new and great achievement. If I shall not be able to write the second part of my Logic, ${ }^{26}$ no harm will be done to our common cause, since my project is to a large degree fulfilled in your book. $[. .$.$] But this is less interesting for you than my present view about the difference in the$ disposition from which you have started. Despite the fact that the concerns about agreement between us seem to me unfounded [...] Yet, I admittedly confess, that after my first reading of your book I still cannot discard as wrong what I told you in Marburg: you put the center of gravity upon the concept of relation and you believe that you have accomplished with the help of this concept the idealization of all materiality. The expression even escaped you that the concept of relation is a category; yet it is a category only insofar as it is function, and function unavoidably demands the infinitesimal element in which alone the root of the ideal reality can be found (Cohen to Cassirer, 10 Aug. 1910, ECN, Doc. 45, 269; part. trans. in Gawronsky, 1949, 21).

Cassirer's response has not been preserved. However, he clearly would have disagreed with Cohen's criticism, if only for the simple reason that the notion of function does not actually presuppose that of the infinitesimal or even continuity ${ }^{27}$ In general, the reflection about the infinitesimal calculus does not play any significant role in the work of Cassirer, who had access to more sophisticated mathematical tools (cf. e.g., Ihmig, 1997 for the importance of group theory for Cassirer's work).

Cohen clearly felt that it was Gawronsky, and not Cassirer ${ }^{28}$ who had grasped and defended his core message. The leitmotif of Cassirer's book, the priority of the relation over the relata, completely obscured Cohen's insistence that the problem was the 'origin' of the relata themselves; in contrast, Gawronsky had grasped this perfectly well: "The more excited I am now about your judgment concerning Gawronsky," Cohen admitted to Cassirer in the same letter, "you will understand by my grateful bias towards him" (Cohen to Cassirer, 10 Aug. 1910, ECN, Doc. 45, 269).

\section{Finis Marburgi: The Decline of the 'Marburg school'}

In 1912, at the age of seventy, Cohen retired from his chair at Marburg and moved to Berlin, where he began teaching at the Lehranstalt für die Wissenschaft des Judentums, and through his published essays continued to take part in the debates concerning German Judaism. On the occasion of Cohen's seventieth birthday, Natorp and Görland planned to edit a Festschrift in his honor. Cassirer also suggested dedicating a special issue of the Kant-Studien to him (cf. Natorp and Görland, 17 February 1911; Holzhey, 1986, Br. 124, 395). The correspondence between Natorp and Görland is an important document for understanding the atmosphere of finis Marburgi in which both of the celebrative collections were prepared: "In the meantime the 'Marburg school' is in serious danger of being thrown awry" (Natorp wrote to Görland on 6 June 1912; Holzhey, 1986, Br. 131, 2:411). On 22 May 1912, Gawronsky was refused his habilitation (Sieg, 1994, 360f.);

\footnotetext{
${ }^{26}$ Cohen, following Natorp's suggestion, wrote the logic in a purely systematic way with the intent of covering the historical details in a second volume, which was never written..

${ }^{27} \mathrm{Cf}$. also the later remarks of Gawronsky $(1949,21)$, who, many decades later, seems to have become surprisingly dismissive of Cohen's approach.

${ }^{28}$ See also the testimony of Abraham Fraenkel-mostly remembered for the so-called Zermelo-Fraenkel set theory — who was a student in Marburg at that time Fraenkel, 1967, 109.
} 
hanging over the celebration was the Damocles' sword that an empirical psychologist might be replacing Cohen as chair. Moreover, some of the most promising young members of the school, Nicolai Hartmann and Heinz Heimsoeth (the latter of which was working on his H. Heimsoeth, 1912-1914), were expressing dissatisfaction about the Marburg orthodoxy (F. Hartmann and R. Heimsoeth, 1978).

After the publication of the special issue of the Kant-Studien, Heimsoeth wrote to Hartmann: "But then, alas, we have the four papers by Natorp [1912], Görland [1912], Cassirer [1912] u. Kinkel [1912]. How sad are things in Marburg. Should they all really say the same things? More precisely: should they all repeat the same words?" (Heimsoeth to Hartmann, 10 July 1912; F. Hartmann and R. Heimsoeth, 1978, 118). The dissatisfaction over Cassirer's contribution is especially evident: "From Cassirer in particular I do not hope for anything more after this paper. Never ever. One should simply look at the style" (Heimsoeth to Hartmann, 10 July 1912; F. Hartmann and R. Heimsoeth, 1978, 119).

Yet Cassirer's paper (Cassirer, 1912, cf. Moynahan, 2003, 56ff.) seems to do just what it was supposed to do, that is, present the main features of Cohen's interpretation of Kant. However, Cassirer also carefully avoided confronting Cohen's most controversial claims, e.g., the identification of the differential with the 'intensive reality'. Heimsoeth's impatience with Cassirer is somewhat understandable: "At least once in his life, could't Cassirer write for others, so that someone would actually read the Cohen special issue?" (Heimsoeth to Hartmann, 10 July 1912 F. Hartmann and R. Heimsoeth, 1978, 119). However, the problem might be the exact opposite: Cassirer wrote precisely for 'others'. As in all his (relatively few) writings that he dedicated to Cohen (Cassirer, 1918, 1920, 1926, 1943), Cassirer tried to present the counterintuitive aspects of his beloved teacher's philosophy in a language comprehensible to people outside of Marburg; at the same time, however, he avoided philosophically engaging their deep theoretical meanings. It is not surprising that in the last 1914 edition of his "Kritischen Nachtrag" to Lange's history of materialism (Cohen, 1914,), Cohen refers us to Gawronsky's book as a useful update of his views on the 'infinitesimal', yet he does not even mention Cassirer or Natorp's monographs (Cohen, 1914,).

Cohen died on 4 April 1918. If one is looking for a passage in which Cassirer expressed what he accepted of Das Princip der Infinitesimal-Methode, one can perhaps find it where it is least expected, in Cassirer's monograph on the theory of relativity, finished in 1920:

The velocity of a material system is more than a mere factor for calculation; it not only really belongs to the system but defines its reality since it determines its vis viva, i.e., the measure of its dynamic effectiveness. In the differential quotient of the space over the time, Galileo's physics claims to have reached the kernel of all physical being, to have defined the intensive reality of motion. By this reality, the dynamic consideration is distinguished from the merely phoronomic [...] Leibniz, too, in his foundation of dynamics, remains throughout at this standpoint [...] Motion conceived as a mere change of place in the purely phoronomical sense, he explains, always remains something purely relative; it only becomes an expression of a true physical and metaphysical reality when we add to it an inner dynamic principle, a force (Cassirer, 1921, 21).

This passage shows that what Cassirer accepted from Cohen's 1883 book was the 'urbanized' version Lasswitz had suggested (section 5) (for whom Cassirer always showed great respect), and that he himself had presented in his own book on Leibniz (section 3.2). The 'intensive reality' is the dynamic element which distinguishes physical motion from the merely phoronomic/geometrical one; it was in the attempt to give conceptual expression that the conceptual tools were discovered that contained, in embryo, the later methods for analyzing the infinite. This was probably the 
best way of 'making sense' of Cohen, ${ }^{29}$ especially if one avoids, as Cassirer did, the somewhat bolder identification of the intensive reality with the 'differential'. However, needless to say, this topic does not play any significant role in Cassirer's book on relativity.

Sixty years later, in a completely different environment, nearly nothing remained of Cohen's approach to the infinitesimal calculus. Das Princip der Infinitesimal-Methode (Cohen, 1883) was an unsuccessful book. There was no significant reception in the world outside of Marburg, where it never rose to the status of a reliable source for the history of the infinitesimal calculus. Within Marburg the book was an awkward presence: its conclusions had to be defended from hostility (section 4, section 6.2), yet they could not be fully embraced without qualifications. The central concept of the calculus, as many around Cohen must have pointed out to him even in private conversation, is not the the 'differential', but the 'differential quotient' as calculus textbooks say. The latter concept, after all, offers the most clear example of relations without relata that critical idealism is searching for. However, as we have seen, Cohen's stubborn reluctance to follow an apparently sensible piece of advice, was motivated by the fact that, for better or worse, he was searching for something deeper, something that could account for the relata themselves. As a result, however, one cannot even credit Das Princip der Infinitesimal-Methode for having paved the way to Cassirer's 'structuralism' (Reck, 2003; Yap, 2014), undeniably the most successful product of Marburg Neo-Kantianism.

The impact of an unsuccessful book: this is what we have termed 'the puzzle of Cohen's Infnitesimalmethode'. The puzzle can be solved insofar as one can separate the book's method of investigation from the results it achieved. If Das Princip der Infinitesimal-Methode failed to meet the standards of historical scholarship, more than any other book it embodied a certain style of doing philosophy, where the armchair speculation of post-Kantian idealism was replaced by a detailed confrontation with the historical developments of the sciences. It is this style that survived in the much more successful works of Natorp, Lasswitz and Cassirer, as well as in the work of several minor figures like De Portu, Görland, Buek, etc. (cf. Ferrari, 1996, 20ff.). Boris Pasternakwinner of the 1958 Nobel Prize in Literature, and one of the many Russian émigrés who studied in Marburg (Mallac, 1979) — put it beautifully in his brief 1931 autobiography (Pasternak, 1931): "the school did not speak of the stages in the development of the Weltgeist, but, say, of the postal correspondence of the Bernoulli family; though it knew that every thought of however distant a time [...] must be laid bare to our logical commentary" (Pasternak, 1931, cited from Pasternak, $1949,42)$.

\section{Abbreviations}

A Immanuel Kant (1781). Critik der reinen Vernunft. 1st ed. Riga: Johann Friedrich Hartknoch. Repr.in Ak. 4.

Ak. Immanuel Kant (1900). Kant's gesammelte Schriften. Ed. by Preussische Akademie der Wissenschaften, Berlin-Brandenburgische Akademie der Wissenschaften, and Akademie der Wissenschaften in Göttingen. 29 vols. Berlin: Reimer. 28 volumes are published so far.

\footnotetext{
${ }^{29}$ This is the point where I most disagree with the otherwise very stimulating paper of Mormann and Katz (2013). Without mentioning Lasswitz, they seem to choose an exclusively 'mathematical' way of 'making sense' of Cohen, resorting ultimately to Abraham Robinson's non-standard analysis, in which the existence of ideal numbers that might be infinitesimally small or infinitesimally large compared with the real numbers is "fully vindicated" (Robinson, 1974 2). In my opinion, however, this obscures at least two central features of Cohen's approach (or at least of the 1883 version of it): first, the reference to mechanics, and second, the historical dimension of Cohen's investigation. In the history of science the infinitesimals were introduced to conceptually secure the 'reality' of motion: in this way, in Cohen's view, the Erkenntisskritk would provide a foundation for the infinitesimals, where mathematics could not. Not surprisingly, this last aspect of Cohen's endeavor does not seem to have enjoyed great favor.
} 

Ak. 3.

CW Hermann Cohen (1977-). Werke. Ed. by Helmut Holzhey. 14 vols. Hildesheim: Olms.

ECN Ernst Cassirer (1995-). Nachgelassene Manuskripte und Texte. Ed. by John Michael Krois. 18 vols. Hamburg: Meiner.

ECW Ernst Cassirer (1998-). Gesammelte Werke. Hamburger Ausgabe. Ed. by Birgit Recki. 26 vols. Hamburg: Meiner.

GM Gottfried Wilhelm Leibniz (1850). Leibnizens mathematische Schriften. Ed. by Carl Immanuel Gerhardt. 7 vols. Halle: Schmidt.

\section{References}

Angelelli, Ignacio, ed. (1967). Kleine Schriften. Wissenschaftliche Buchgesellschaft: Darmstadt/Hildesheim. Beiser, Frederick C. (2014). The Genesis of Neo-Kantianism, 1796-1880. Oxford: Oxford University Press. Beller, Mara (2000). "Kant's Impact on Einstein's Thought". In: Einstein. The Formative Years 1879 - 1909 Ed. by Don Howard and John Stachel. Boston: Birkhäuser.

Bos, Henk J. (1974). "Differentials, higher-order differentials, and the derivative in the Leibnizian calculus". Archive for History of Exact Sciences 14, 1-90.

- (1986). "Fundamental concepts of the Leibnizian calculus". In: 300 Jahre "Nova Methodus" von G.W. Leibniz (1684-1984). Ed. by Albert Heinekamp. Wiesbaden-Stuttgart: Steiner, 103-18.

Bottazzini, Umberto (1986). The Higher Calculus: A History of Real and Complex Analysis from Euler to Weierstrass. New York: Springer.

Breger, Herbert (1986). "Leibniz, Weyl und das Kontinuum". In: Beiträge zur Wirkungs- und Rezeptionsgeschichte von Leibniz. Ed. by Albert Heinekamp. Wiesbaden: Steiner, 316-330.

Buek, Otto (1904). "Die Atomistik und Faradays Begriff der Materie". Archiv für Geschichte der Philosophie 18, $65-139$.

Cantor, Georg (1872). "Ueber die Ausdehnung eines Satzes aus der Theorie der trigonometrischen Reihen". Mathematische Annalen 5 (1), 123-132.

- (1879). "Ueber unendliche, lineare Punktmannichfaltigkeiten". Mathematische Annalen 15 (1), 1-7.

- (1884). "Review of Cohen, Das Princip der Infinitesimal-Methode (Cohen, 1883)". Deutsche Literaturzeitung $5,266-8$.

Carnot, Lazare (1881). Réflexions sur la métaphysique du calcul infinitésimal. Paris: Blanchard.

Cassirer Bondy, Toni (1981). Mein Leben mit Ernst Cassirer. Hildesheim: Gerstenberg.

Cassirer, Ernst (1902). Leibniz' System in seinen wissenschaftlichen Grundlagen. Marburg: Elwert. Repr.in ECW, vol. 1.

- (1906a). Das Erkenntnisproblem in der Philosophie und Wissenschaft der neueren Zeit. Vol. 1. Berlin: Bruno Cassirer. Repr.in ECW vol. 2.

- (1906b). Der kritische Idealismus und die Philosophie des 'gesunden Menschenverstandes'. Ed. by Hermann Cohen and Paul Natorp. Giessen, Germany: Töpelmann. Repr.in ECW, Vol. 9, 3-36.

- (1906c). "Substanzbegriff und Funktionsbegriff". Probevorlesung an der Königlichen Friedrich-WilhelmsUniversität in Berlin (26. July 1906). Printed in ECN, 8:3-16.

- (1907a). Das Erkenntnisproblem in der Philosophie und Wissenschaft der neueren Zeit. Vol. 2. Berlin: Bruno Cassirer. Repr.in ECW] vol. 3.

- (1907b). "Kant und die moderne Mathematik. Mit Bezug auf Bertrand Russell und Louis Couturats Werke über die Prinzipien der Mathematik". Kant-Studien 12 (1-3), 1-49. Repr. in ECW 9, 37-82.

- (1907c). "Zur Frage nach der Methode der Erkenntniskritik. Eine Entgegnung". Vierteljahrsschrift für wissenschaftliche Philosophie und Soziologie 31, 441-465. Repr.in ECW, vol. 9, 83-103.

- (1909). "'Persönliche' und 'sachliche' Polemik. Ein Schlusswort". Vierteljahrsschrift für wissenschaftliche Philosophie und Soziologie 33, 181-184. Repr.in ECW vol. 9, 444-446.

- (1910). Substanzbegriff und Funktionsbegriff. Untersuchungen über die Grundfragen der Erkenntniskritik. Berlin: Bruno Cassirer. Repr.in ECW, vol. 6.

- (1912). "Hermann Cohen und die Erneuerung der Kantischen Philosophie". Kant-Studien 17, 252-273.

- (1918). "Zur Lehre Hermann Cohens". 4. April 1918. Berliner Tageblatt und Handels-Zeitung (47), 2. Repr ECW, Vol. 9, 494-497.

- (1920). "Hermann Cohen". Korrespondenzblatt des Vereins zur Gründung und Erhaltung einer Akademie für die Wissenschaft des Judentums 1, 1-10. Repr.in ECW vol. 9, 498-509.

- (1921). Zur Einsteinschen Relativitätstheorie. Erkenntnistheoretische Betrachtungen. Berlin: B. Cassirer. Repr.in ECW vol. 10.

- (1926). "Von Hermann Cohens geistigem Erbe". Almanach des Verlages Bruno Cassirer, 53-63. Repr.in ECW vol. $16,480-486$. 
Cassirer, Ernst (1943). "Hermann Cohen, 1842-1918". Social Research. An International Quarterly of Political and Social Science 10, 219-232. Repr.in ECW] vol. 24, 161-173.

Cohen, Hermann (1871). Kants Theorie der Erfahrung. 1st ed. Berlin: Dümmler. Repr.in CW, vol. 1/III.

- (1876). "Friedrich Albert Lange". Preussische Jahrbücher 37, 353-81. Repr.in Cohen, 1928, 2:357-391.

- (1877). Kants Begründung der Ethik. 1st ed. Berlin: Dümmler. Repr.in CW, vol. 2.

- (1878). Platons Ideenlehre und die Mathematik. Marburg: Marburgi Ex officina typographica C.L. Pfeilii.

- (1883). Das Princip der Infinitesimal-Methode und seine Geschichte. Ein Kapitel zur Grundlegung der Erkenntnisskritik. Berlin: Dümmler. Repr.in CW, vol. 5/I.

- (1885). Kants Theorie der Erfahrung. 2nd ed. Berlin: Dümmler. Repr.in CW vol. 1/I.

- (1896). "Einleitung mit kritischem Nachtrag". In: Lange, Friedrich Albert. Geschichte des Materialismus und Kritik seiner Bedeutung in der Gegenwart. 5th ed. Leipzig: Verlag von J. Baedeker. Repr.in CW vol. 5/II.

- (1902). Logik der reinen Erkenntnis. Berlin: B. Cassirer. repr in CW, vol. 6.

- (1910). "August Stadler. Ein Nachruf". Kant-Studien 15, 403-420.

- (1914). "Einleitung mit kritischem Nachtrag". In: Lange, Friedrich Albert. Geschichte des Materialismus und Kritik seiner Bedeutung in der Gegenwart. 3rd ed. Leipzig: Verlag von J. Baedeker. Repr.in CW vol. 5/II.

- (1928). Schriften zur Philosophie und Zeitgeschichte. Ed. by Albert Gorland and Ernst Cassirer. Berlin: B. Cassirer.

- (2015). Briefe an August Stadler. Ed. by Hartwig Widebach. Basel: Schwabe.

Cournot, Antoine Augustin (1841). Traité élémentaire de la théorie des fonctions et du calcul infinitésimal. Paris: Hachette.

Couturat, Louis (1901). La logique de Leibniz d'après des documents inédits. Paris: Alcan.

Darrigol, Olivier (2003). "Number and Measure: Hermann von Helmholtz at the Crossroads of Mathematics, Physics, and Psychology." Studies in the History of the Philosophy of Science 34, 515-73.

Dedekind, Richard (1872). Stetigkeit und irrationale Zahlen. Braunschweig: Vieweg.

Diderot, Denis and Jean Le Rond d'Alembert (1751-1772). Encyclopédie ou Dictionnaire raisonné des Sciences, des Arts et des Métiers. 28 vols. Paris: Chez Briasson.

Du Bois-Reymond, Paul (1877). "Ueber die Paradoxen des Infinitärcalcüls". Mathematische Annalen 11, 149-167.

Dühring, Eugen (1873). Kritische Geschichte der allgemeinen Principien der Mechanik. Berlin: Theobald Grieben.

Ebbinghaus, Julius (1959). "Zur Berufung Cohens auf den Marburger Lehrstuhl". Archiv für Philosophie 9, 90-92.

Eccarius, Wolfgang (1985). "Georg Cantor und Kurd Laßwitz. Briefe zur Philosophie des Unendlichen". NTM Schriftenreihe für Geschichte der Naturwissenschaften, Technik und Medizin 22 (1), 29-52.

Edel, Geert (1988). Von der Vernunftkritik zur Erkenntnislogik. Die Entwicklung der theoretischen Philosophie Cohens. Freiburg: Alber.

Edgar, Scott (2014). "Hermann Cohen's Principle of the Infinitesimal Method and its History: a Rationalist Interpretation". Manuscript.

Ehrlich, Philip (2006). "The Rise of non-Archimedean Mathematics and the Roots of a Misconception I. The Emergence of non-Archimedean Systems of Magnitudes". Archive for History of Exact Sciences 60 (1), 1-121.

Elsas, Adolf (1884). "Review of Cohen, Das Princip der Infinitesimal-Methode (Cohen, 1883)". Philosophische Monatshefte 20, 556-560.

- (1885). "Review of Stadler, Kants Theorie der Materie (Stadler, 1883)". Philosophische Monatshefte 21, 144160 .

- (1886). Über die Psychophysik. Physikalische und erkenntnisstheoretische Betrachtungen. Marburg: Elwert.

- (1891). "Review of Lasswitz Geschichte der Atomistik (Lasswitz, 1890)". Zeitschrift für Philosophie und Philosophische Kritik (99), 290-303.

Euler, Leonhard (1748). Introductio in analysin infinitorum. Lousanne: Apud Marcum-Michaelem Bousquet \& socios.

Faraday, Michael (1844). "A Speculation Touching Electric Conduction, and the Nature of Matter". Journal of the Franklin Institute 37 (6), 392-399.

Fechner, Gustav Theodor (1860). Elemente der Psychophysik. Leipzig: Breitkopf \& Härtel.

Ferrari, Massimo (1988). Il giovane Cassirer e la scuola di Marburgo. Milan: Angeli.

- (1996). Ernst Cassirer. Dalla scuola di Marburgo alla filosofia della cultura. Florence: Olschki.

Fraenkel, Abraham Adolf (1967). Lebenskreise. Aus den Erinnerungen eines jüdischen Mathematikers. Stuttgart: Deutsche Verl.-Anst.

Frege, Gottlob (1885). "Review of Cohen, Das Princip der Infinitesimal-Methode (Cohen, 1883)". Zeitschrift für Philosophie und philosophische Kritik 87, 324-9. Rep. Angelelli, 1967, 99-102.

- (1891). "Über das Trägheitgesetz". Zeitschrift für Philosophie und philosophische Kritik 98.

Friedman, Michael (1999). Reconsidering Logical Positivism. New York: Cambridge University Press.

- (2000). A Parting of the Ways. Carnap, Cassirer, and Heidegger. Chicago: Open Court.

- (2010). "Synthetic History Reconsidered. Reinvigorating the Marriage of History and Philosophy of Science". In: ed. by Michael Dickson and Mary Domski. Chicago: Open Court.

Galilei, Galileo (1855-). Le opere. Ed. by Eurgenio Alberi. Firenze: Soc. Ed. Fiorentina.

Galluzzi, Paolo (1979). Momento: studi galileiani. Roma: Ed. dell'Ateneo Bizzarri. 
Gawronsky, Dimitri (1910). Das Urteil der Realität und seine mathematischen Voraussetzungen. Marburg: Dissertation.

- (1949). "Ernst Cassirer: His Life and His Work". In: The Philosophy of Ernst Cassirer. Ed. by Paul Arthur Schilpp. New York: Tudor Publ. Co.

Goedeckemeyer, Albert (1905). "Review of Natorp, Platos Ideenlehre (Natorp, 1903)". Göttingische gelehrte Anzeigen 8, 585-609.

Görland, Albert (1899). Aristoteles und die Mathematik. Marburg: Elwert.

- (1912). "Hermann Cohens systematische Arbeit im Dienste des kritischen Idealismus". Kant-Studien 17, 222251 .

Grelling, Kurt: (1907). Das gute, klare Recht der Freunde der anthropologischen Vernunftkritik verteidigt gegen Ernst Cassirer. 2: Abhandlungen der Fries'schen Schule, 153-190.

Habermas, Jürgen (1979). "Urbanisierung der Heideggerschen Provinz: Laudatio auf Hans-Georg Gadamer aus Anlaß der Verleihung der Hegel-Preises der Stadt Stuttgart, 1979". In: Das Erbe Hegels: Zwei Reden aus Anlass der Verleihung des Hegel-Preises 1979 der Stadt Stuttgart an Hans-Georg Gadamer am 13. Juni 1979. Ed. by Jürgen Habermas and Hans Georg Gadamer. Frankfurt am Main: Suhrkamp, 9-31.

Hahn, Hahn (1907). "Über die nichtarchimedischen Größensysteme". Sitzungsberichte der Kaiserlichen Akademie der Wissenschaften, Wien, Mathematisch - Naturwissenschaftliche Klasse 16, 601-655.

Hartmann, Frida and Renate Heimsoeth, eds. (1978). Nicolai Hartmann und Heinz Heimsoeth im Briefwechsel. Bonn: Bouvier.

Hartmann, Nicolai (1908). "Über das Seinsproblem in der griechischen Philosophie vor Plato". Inaugural-Dissertation. Universität Marburg. 27 July 1907.

Heidelberger, Michael (2004). Nature from Within. Gustav Theodor Fechner and His Psychophysical Worldview. Pittsburgh, PA: University of Pittsburgh Press.

Heimsoeth, Heinz (1912-1914). Die Methode der Erkenntnis bei Descartes und Leibniz. Giessen: Töpelmann.

Heis, Jeremy (2011). "Ernst Cassirer's Neo-Kantian Philosophy of Geometry". British Journal for the History of Philosophy 19 (4), 759-794.

Hertz, Heinrich (1892). Untersuchungen ueber die Ausbreitung der elektrischen Kraft. Leipzig: Barth.

Hessenberg, Gerhard (1908). "'Persönliche' und 'sachliche' Polemik". Vierteljahrsschrift für wissenschaftliche Philosophie und Soziologie 32, 402-408.

Holzhey, Helmut (1984). "Das philosophische Realitätsproblem. Zu Kants Unterscheidung von Realität und Wirklichkeit". In: 200 Jahre Kritik der reinen Vernunft. Ed. by Joachim Kopper and Wilhelm Marx. Hildesheim, Germany: Olms.

- (1986). Cohen und Natorp. 2 vols. Basel: Schwabe.

Husserl, Edmund (1994-). Briefwechsel. Ed. by Samuel Ijsseling. Dordrecht: Kluwer.

Ihmig, Karl-Norbert (1997). Cassirers Invariantentheorie der Erfahrung und seine Rezeption des Erlanger Programms. Hamburg: Meiner.

Kant, Immanuel (1786). Metaphysische Anfangsgründe der Naturwissenschaft. Riga: Johann Friedrich Hartknoch. Repr.in Ak. 4:465-565.

- (1790). Critik der Urtheilskraft. Berlin/Libau: bey Lagarde und Friederich.

Kinkel, Walter (1912). "Das Urteil des Ursprungs". Kant-Studien 17, 274-282.

Lagrange, Joseph-Louis (1797). Théorie des fonctions analytiques. Paris: L'Imprimerie de la République.

Lange, Friedrich Albert (1866). Geschichte des Materialismus und Kritik seiner Bedeutung in der Gegenwart. Iserlohn: Verlag von J. Baedeker.

- (1896). Geschichte des Materialismus und Kritik seiner Bedeutung in der Gegenwart. 5th ed. Leipzig: Verlag von J. Baedeker.

Lasswitz, Kurd (1878). Atomistik und Kriticismus. Ein Beitrag zur erkenntnistheoretischen Grundlegung der Physik. Vieweg u. Sohn: Braunschweig.

- (1884). "Giordano Bruno und die Atomistik". Vierteljahrsschrift für wissenschaftliche Philosophie 8, 18-55.

- (1885a). "Review of Cohen, Das Princip der Infinitesimal-Methode (Cohen, 1883)". Vierteljahrsschrift für wissenschaftliche Philosophie und Soziologie 9, 494-503.

- (1885b). "Zur Rechtfertigung der kinetischen Atomistik". Vierteljahrsschrift für wissenschaftliche Philosophie (9), 137-161.

- (1887). "Review of Elsas, Über die Psychophysik. Physikalische und erkenntnisstheoretische Betrachtungen (Elsas, 1886)". Deutsche Literaturzeitung 8, 3-4.

- (1888a). "Das Problem der Continuität". Philosophische Monatshefte 24, 9-36.

- (1888b). "Galileis Theorie der Materie, I". Vierteljahrsschrift für wissenschaftliche Philosophie 4, 458-476.

- (1889). "Galileis Theorie der Materie, II". Vierteljahrsschrift für wissenschaftliche Philosophie 13, 32-50.

- (1890). Geschichte der Atomistik. 2 vols. Hamburg-Leipzig: Voss.

Leibniz, Gottfried Wilhelm (1850). Leibnizens mathematische Schriften. Ed. by Carl Immanuel Gerhardt. 7 vols. Halle: Schmidt.

- (1904-1906). Hauptschriften zur Grundlegung der Philosophie. Ed. by Ernst Cassirer. Trans. by Arthur Buchenau. 2 vols. Hamburg: Felix Meiner Verlag. 
L'Huilier, Simon (1786). Exposition élémentaire des Principes des calculs supérieurs. Berlin: Decker.

Makkreel, Rudolf A. and Sebastian. Luft (2010). Neo-Kantianism in Contemporary Philosophy. Bloomington: Indiana University Press.

Mallac, Guy de (1979). "Pasternak and Marburg". Russian Review 38 (4), 421-433.

Meyerhof, Otto (1907). "Der Streit um die psychologische Vernunftkritik. Die Fries'sche Schule und ihre Gegner". Vierteljahrsschrift für wissenschaftliche Philosophie und Soziologie 31, 421-439.

Mormann, Thomas and Mikhail Katz (2013). "Infinitesimals as an Issue of Neo-Kantian Philosophy of Science". HOPOS: The Journal of the International Society for the History of Philosophy of Science 3 (2), 236-280.

Moynahan, Gregory B. (2003). "Hermann Cohen's Das Prinzip der Infinitesimalmethode, Ernst Cassirer, and the Politics of Science in Wilhelmine Germany". Perspectives on Science 11 (1), 35-75.

Müller, Ferdinand August (1882). Das Axiom der Psychophysik und die psychologische Bedeutung der Weber'schen Versuche. Marburg: Elwert.

- (1886). Das Problem der Continuität im Mathematik und Mechanik. Historische und systematische Beiträge. Elwert: Marburg.

Natorp, Paul (1881). "Leibniz und der Materialismus". First pub. in Helmut Holzhey. "Paul Natorp: Leibniz und der Materialismus (1881). Aus dem Nachlaß herausgegeben". Studia Leibnitiana 17 (1), 3-14.

- (1882a). Descartes' Erkenntnisstheorie. Eine Studie zur Vorgeschichte des Kriticismus. Marburg: Elwert.

- (1882b). "Galilei als Philosoph. Eine Skizze". Philosophische Monatshefte 18, 193-229.

- (1884). Forschungen zur Geschichte des Erkenntnisproblems im Altertum. Protagoras, Demokrit, Epikur und die Skepsis. Berlin: Hertz.

- (1887). "Über objective und subjective Begründung der Erkenntnis". Philosophische Monatshefte (23), 257286.

- (1888). Einleitung in die Psychologie nach kritischer Methode. Rede, gehalten bei der Gedächtnisfeier der Berliner Abt. der Kant-Ges. am 10. Mai 1918. Freiburg: Mohr.

- (1891a). "Quantität und Qualität in Begriff, Urteil und gegenständlicher Erkenntnis". Philosophische Monatshefte 27, 1-32, 129-160.

- (1891b). "Review of Lasswitz, Geschichte der Atomistik (Lasswitz, 1890)". Philosophische Monatshefte 27, 334.

- (1900). "Nombres, temps et espace dans leurs rapports avec les fonctions primitives de la pensée". In: Bibliothèque du Congres international de la Philosophie, vol. 1, Philosophie générale et Métaphysique. Paris: Colin.

- (1901). "Zu den logischen Grundlagen der neueren Mathematik". Archiv für systematische Philosophie und Soziologie 7, 177-209, 372-384.

- (1902a). "Die erkenntniskritischen Grundlagen der Mathematik". Unterrichtsblätter für Mathematik und Naturwissenschaft 8, 2-8.

- (1902b). "Zu Cohens Logik". In: Holzhey, Helmut. Cohen und Natorp. Vol. 2. 2 vols. Basel: Schwabe, 6-40.

- (1902-1909). "Zu Cohens Logik". In: Holzhey, Helmut. Cohen und Natorp. Vol. 2. 2 vols. Basel: Schwabe, $43-78$.

- (1903). Platos Ideenlehre. Eine Einführung in den Idealismus. Leipzig: Dürr.

- (1910). Die logischen Grundlagen der exakten Wissenschaften. Leipzig Berlin: Teubner.

- (1912). "Kant und die Marburger Schule". Kant-Studien 17, 193-221.

Nelson, Leonard (1905). "Review of Cohen, Logik der reinen Erkenntnis (Cohen, 1902)". Göttingische gelehrte Anzeigen 8, 610-630.

Palmerino, Carla Rita (2001). "Galileo's and Gassendi's Solutions to the Rota Aristotelis Paradox. A Bridge between Matter and Motion Theories". In: Late Medieval and Early Modern Corpuscular Matter Theories. Ed. by Christoph Lüthy and John E. Murdoch andWilliam R. Newman. Leiden. Brill.

Pasternak, Boris (1931). Ochrannaja gramota. Leningrad: Isdatel'stwo Pisatelej.

- (1949). Safe Conduct. An Autobiography and Other Writings. New York, NY: New Directions Publishing Corporation.

Peckhaus, Volker (1990). Hilbertprogramm und kritische Philosophie. Das Göttinger Modell interdisziplinärer Zusammenarbeit zwischen Mathematik und Philosophie. Göttingen: Vandenhoeck u. Ruprecht.

Planck, Max (1887). Das Princip Der Erhaltung der Energie. Leipzig: Teubner.

Poma, Andrea (1997). The Critical Philosophy of Hermann Cohen. Albany, NY: State University of New York Press. Trans. of La filosofia critica di Hermann Cohen. Milano: Mursia, 1989.

Portu, Enrico Stefano Maria de (1904). Galileis Begriff der Wissenschaft. Marburg: Elwert.

Reck, Erich H. (2003). "Dedekind's Structuralism: An Interpretation and Partial Defense". Synthese 137 (3), $369-419$.

Riemann, Bernhard (1869). Partielle Differentialgleichungen und deren Anwendung auf physikalische Fragen. Ed. by Karl Hattendorff. Braunschweig: F. Vieweg.

Robinson, Abraham (1974). Non-standard Analysis. Princeton: Princeton University Press.

Russell, Bertrand (1900). A Critical Exposition of the Philosophy of Leibniz. With an Appendix of Leading Passages. Cambridge: Cambridge Univerity Press. 
Russell, Bertrand (1903). The Principles of Mathematics. Cambridge: Cambridge University Press.

Rutherford, Donald (2008). "Leibniz on Infinitesimals and the Reality of Force. Controversies between Leibniz and his Contemporaries". In: Infinitesimal Differences. Ed. by Ursula Goldenbaum and Douglas Michael. Jesseph. Berlin/New York: De Gruyter, 255-280.

Ryckman, Thomas (2005). The Reign of Relativity. Philosophy in Physics 1915-1925. Oxford/New York: Oxford University Press.

Schulthess, Peter (1984). "Einleitung zu: Cohen Das Princip der Infinitesimal-Methode". In: $C W \mid$ Vol. 5/I.

Sieg, Ulrich (1994). Aufstieg und Niedergang des Marburger Neukantianismus. Die Geschichte einer philosophischen Schulgemeinschaft. Würzburg.

Simon, Max (1898). "Zur Geschichte und Philosophie der Differentialrechnung". Abhandlungen zur Geschichte der mathematischen Wissenschaften 8, 113-132. Vortrag gehalten auf der Naturforscher Versammlung zu Frankfurt in der Section für Math.-Naturw. Unterricht.

Spencer, J.Brookes (1967). "Boscovich's Theory and its Relation to Faraday's Researches: An Analytic Approach". Archive for History of Exact Sciences 4 (3), 184-202.

Stadler, August (1874). Kants Teleologie und ihre erkenntnisstheoretische Bedeutung. Eine Untersuchung. Berlin: Dümmler.

- (1876). Die Grundsätze der reinen Erkenntnisstheorie in der Kantischen Philosophie. Kritische Darstellung. Leipzig: Hirzel.

- (1878). "Über die Ableitung des Psychophysischen Gesetzes". Philosophische Monatshefte 14, $215-23$.

- (1880). "Das Gesetz der Stetigkeit bei Kant". Philosophische Monatshefte 16, 577-97.

- (1883). Kants Theorie der Materie. Leipzig: Hirzel.

Stolz, Otto (1883). "Die unendlich kleinen Grössen". Berichte des Naturwissenschaftlich-Medizinischen Vereines in Innsbruck 14, 21-43.

- (1891). "Ueber das Axiom des Archimedes". Mathematische Annalen 39, 107-112.

Veronese, Giuseppe (1897). "Sul postulato della continuità". Rendiconti della Reale Accademia dei Lincei 5 (6), $161-167$.

- (1908). "La geometria non-Archimedea". Atti del $4^{\circ}$ Congresso internazionale dei Matematici, Roma 1908 I, $197-208$.

Vivanti, Giulio (1894). Il concetto d'infinitesimo e la sua applicazione alla matematica. Saggio storico. Mantova: G. Mondov.

Willmann, Franc oise (2012). "Leibniz's Metaphysics as an Epistemological Obstacle to the Mathematization of Nature: The View of a Late 19th Century Neo-Kantian, Kurd Lasswitz". In: New essays on Leibniz Reception in Science and Philosophy of Science 1800-2000. Ed. by Ralf Krömer and Yannick Chin-Drian. Basel/New York: 25-39.

Yap, Audrey (2014). "Dedekind and Cassirer on Mathematical Concept Formation". Philosophia Mathematica. 